بعض المتغيرات الكينماتيكية لمرحلتي النهوض والطيران وعلاقتهما بمستوى الانجاز في فعالية الوثب الطويل

أ.م.د عمار علي احسان

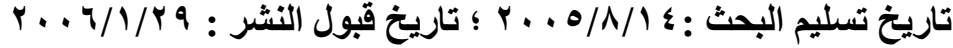

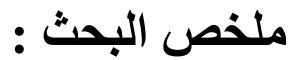

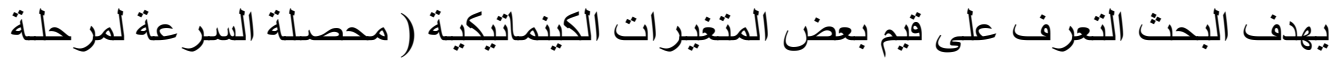

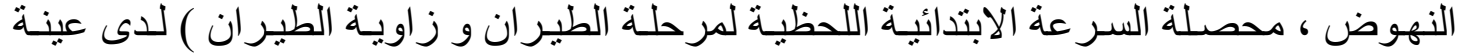

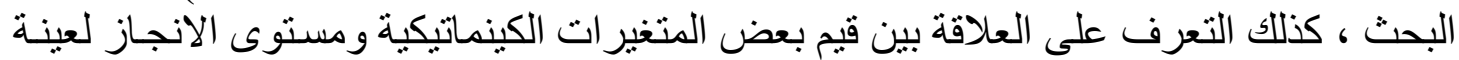

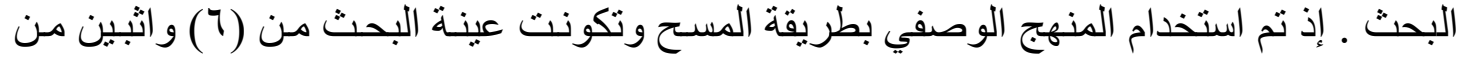

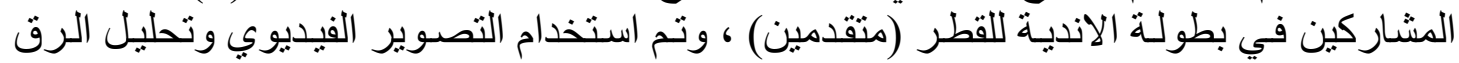

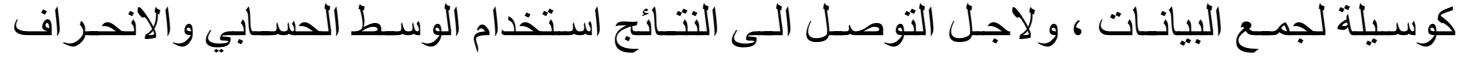

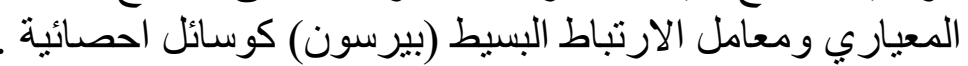

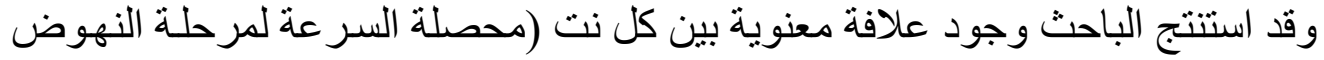

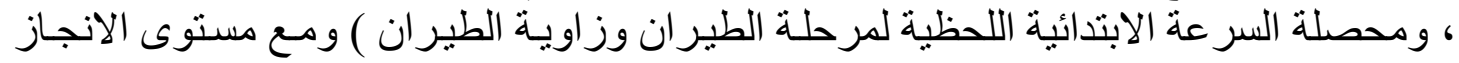

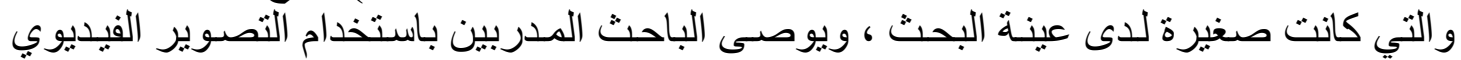

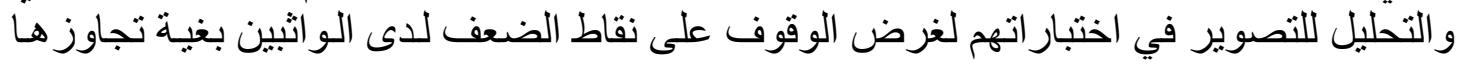

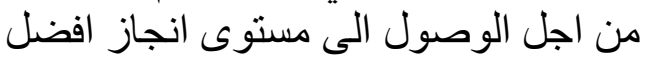

\title{
Some kinematic variables of the rising and flying phases and it relation with the level of achievement in long jump
}

Dr.Amar Ali Ehsaan 


\section{Abstract}

The researcher aims at studying the values of some Kinematic variables such as the speed vector of the take -off phase, the momentary initial speed vector of the flying phase, and the angle of flying in long jump . It also aims at studying the relationship between the values of some of the Kinematic variables, and the level of achievement of the sample in the study .

The survey method has been employed within a descriptive approach . Six long - jump athletes participating in the advanced national club Championship constituted the sample of the study . Video - filming and film analysis have been used as means of data colecting. The statistical methods of the mathematical mean , the standard deviation, and the simple correlation coefficient (Pierson) have been employed to arrive at the result .

The researcher has arrived at the conclusion that there is abstract relationship holding between the speed vector of the rising phase, the momentary initial speed vector of the flying phase, and the level of achievement (which proved to be low in the subjects ).

In this connection, the researchers recommended the use video filming and analysis in carrying out tests in order to find-out precisely the areas of errors, so as to overcome them and arrive at a better level of achievement

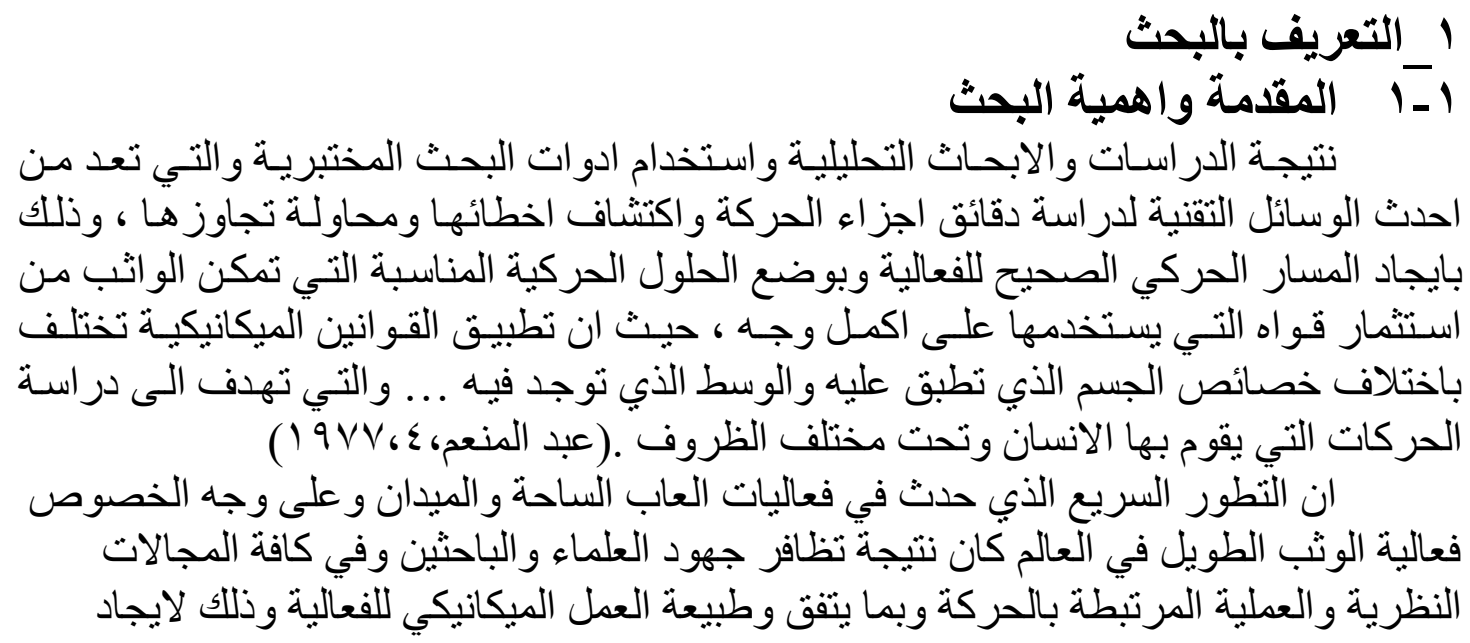




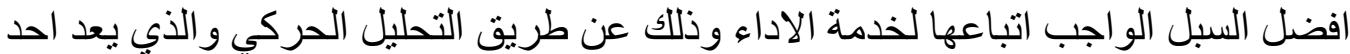

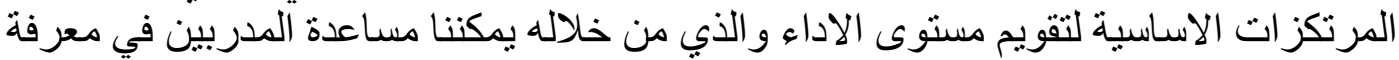

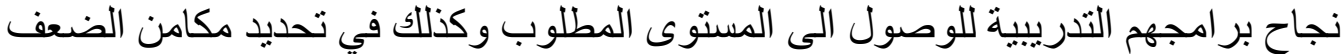

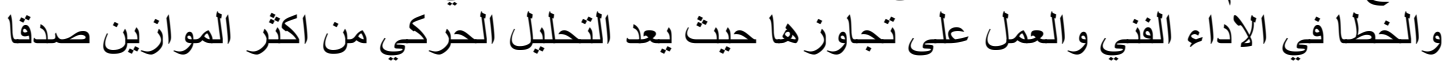

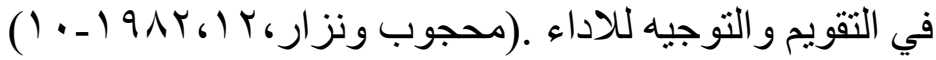

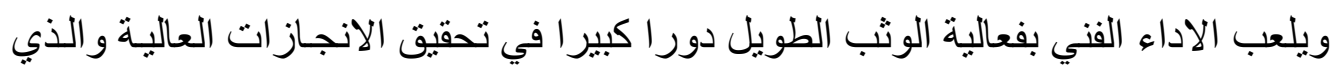

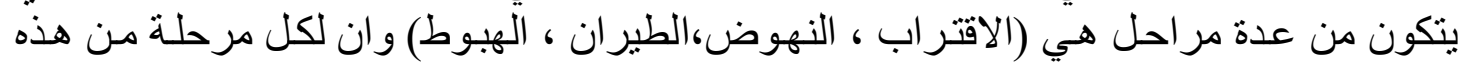

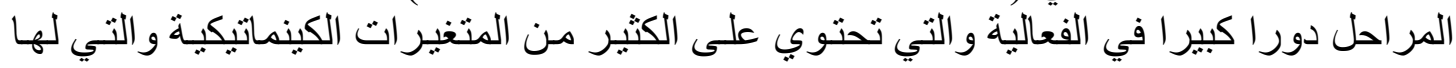
اهية في تحقيق الانجاز العالي ـ العين.

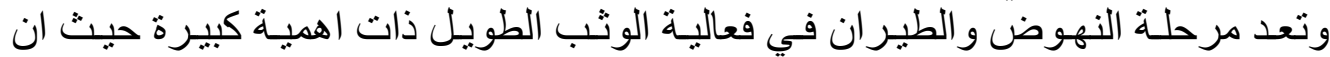

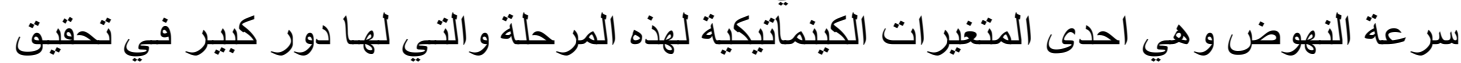

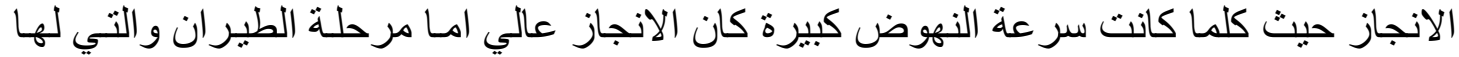

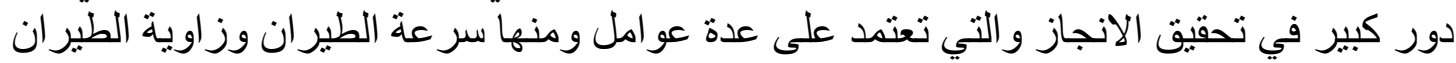

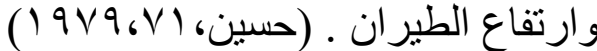

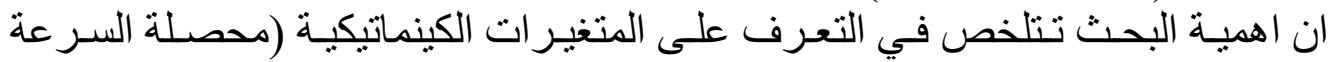

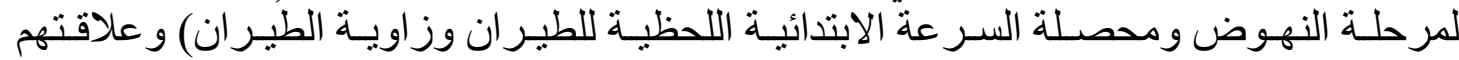

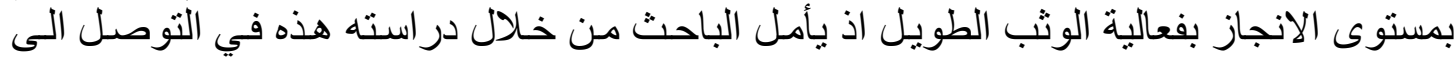

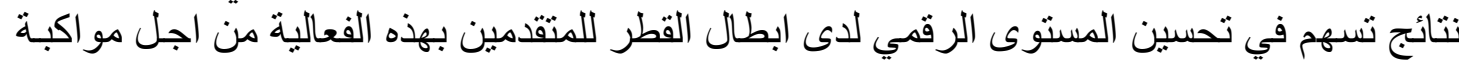

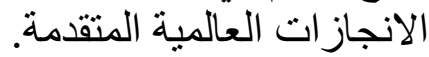

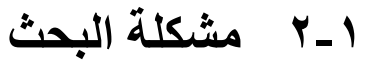

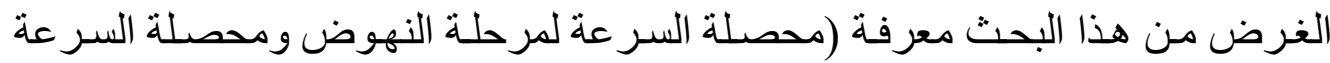

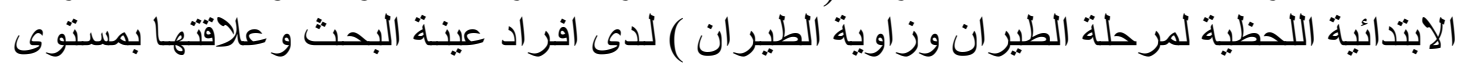

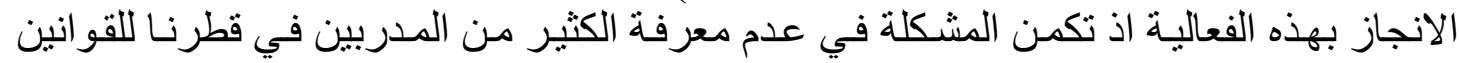

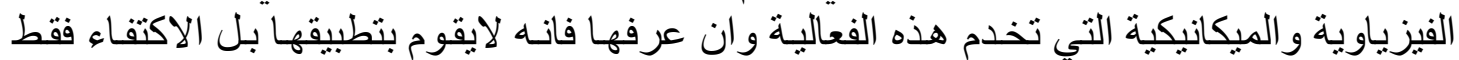

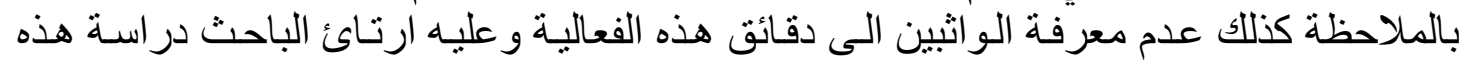

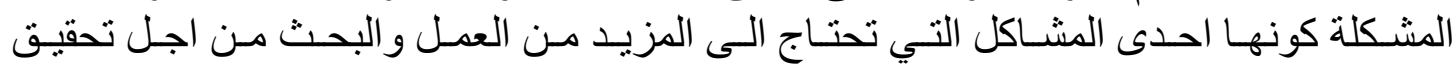

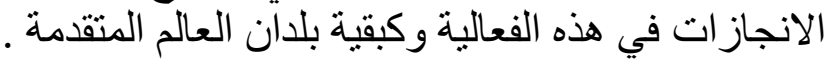

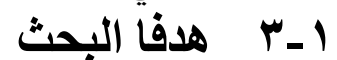

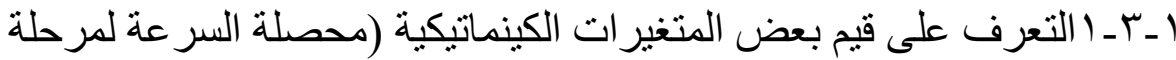

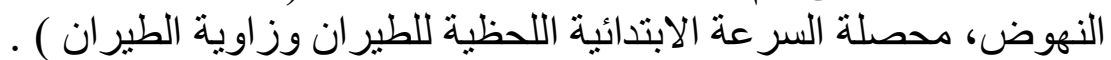

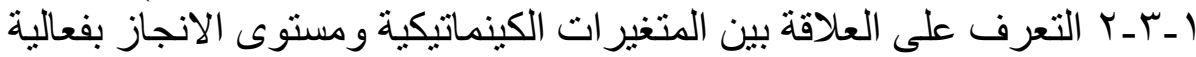

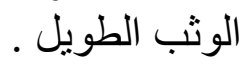
1 ـ ـ فرض البحث ا_ـ ـ ا هناك علاقة معنوية بين المتغير ات الكينماتيكية ومستوى الانجاز.

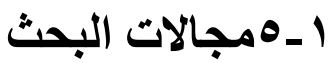

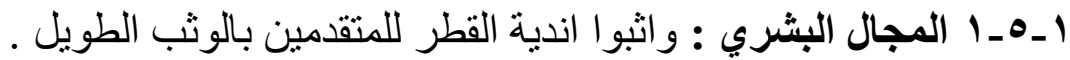

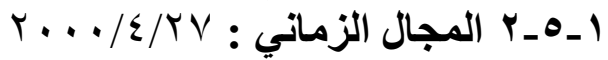

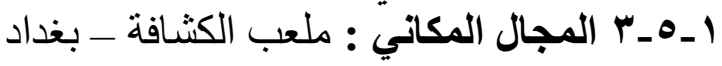




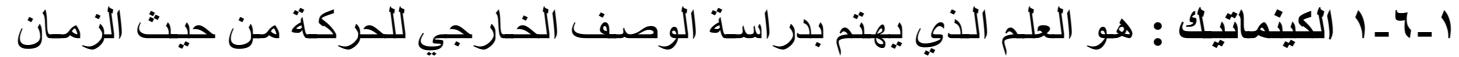

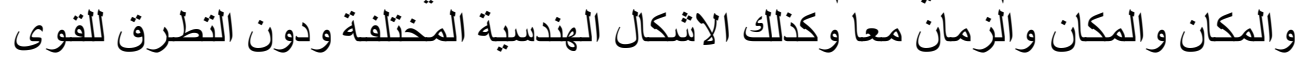

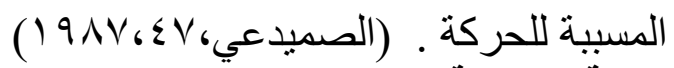

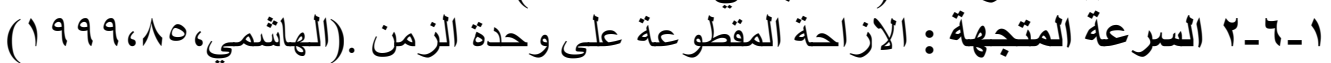

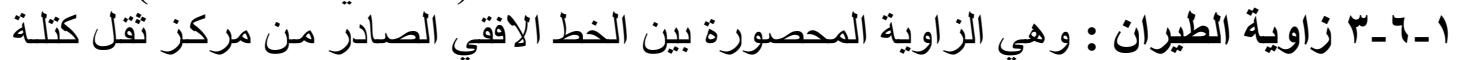

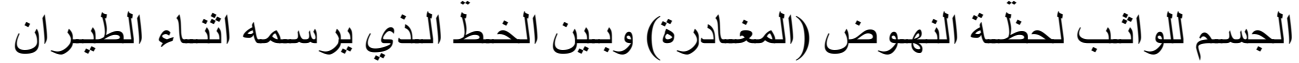

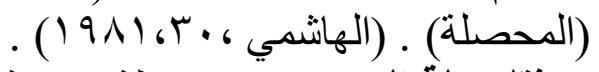

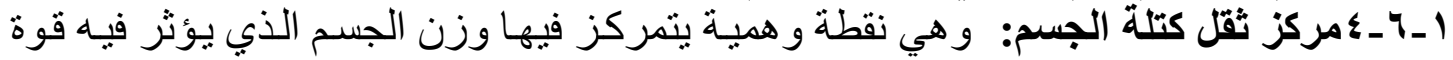

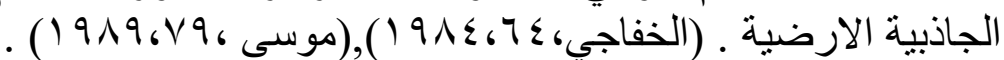

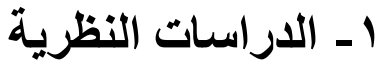

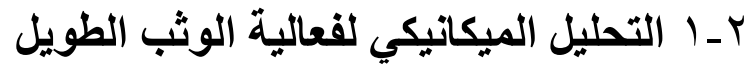

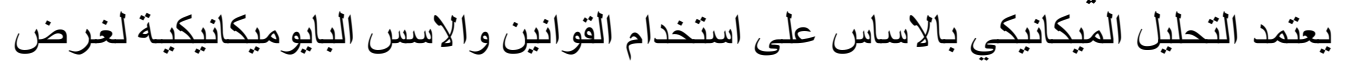

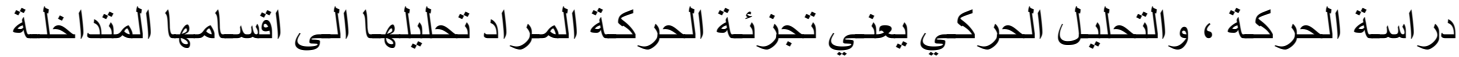

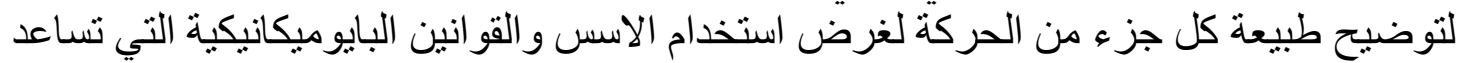

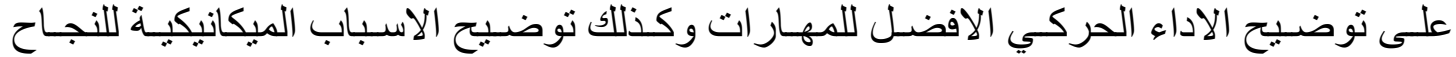

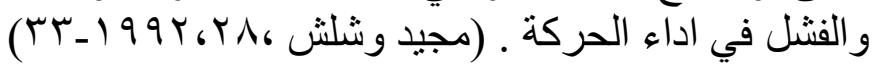

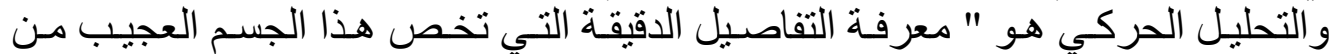

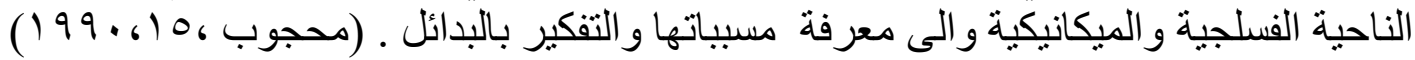

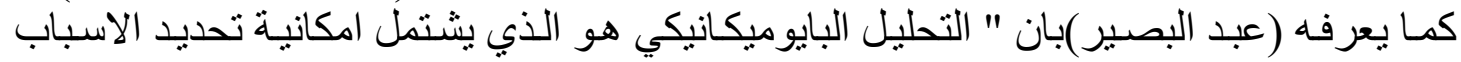

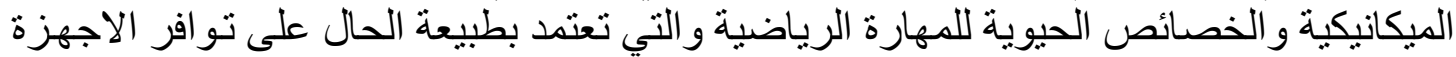

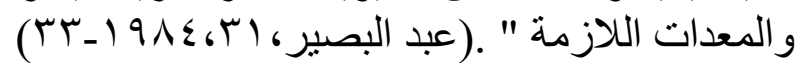

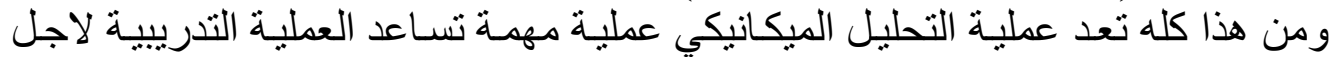

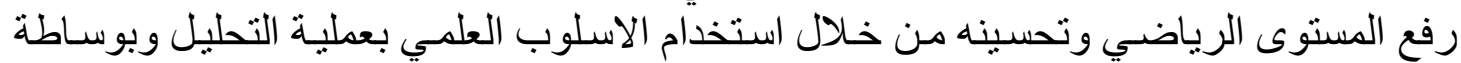

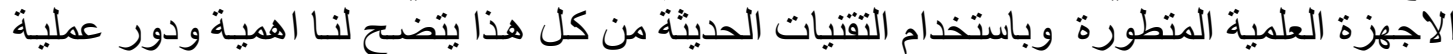

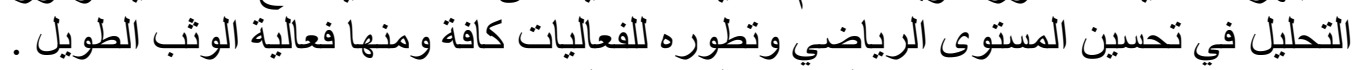

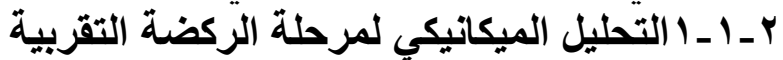

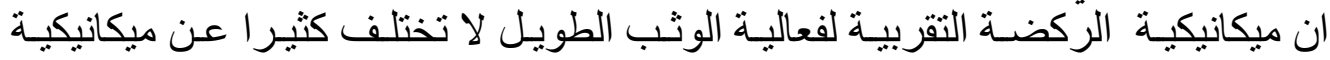

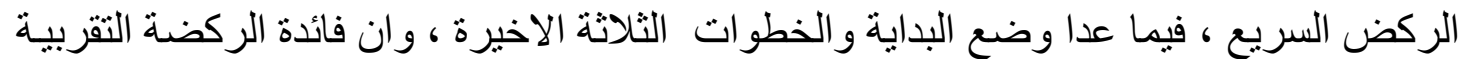

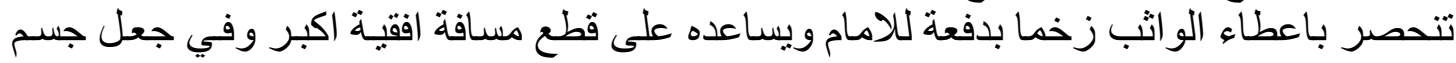

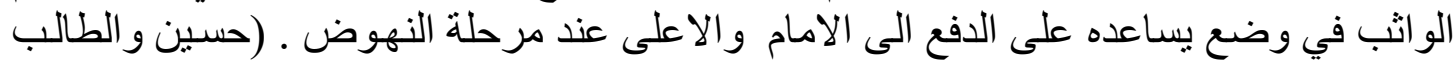

(191966) 19 ،

وتقسم هذه المرحلة الى قسمين رئيسين هما :

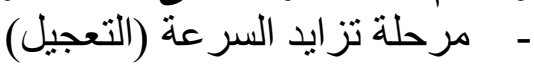

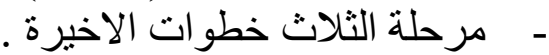

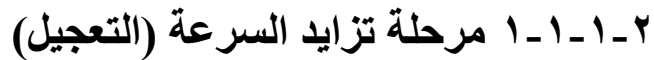

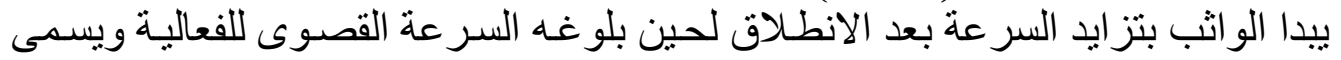

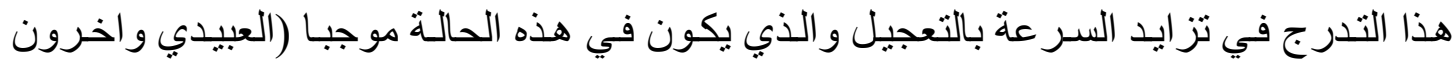

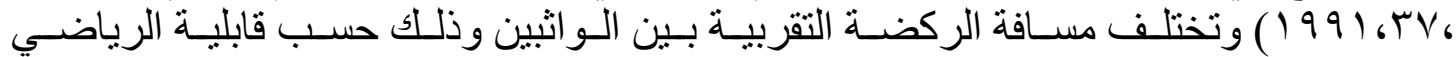

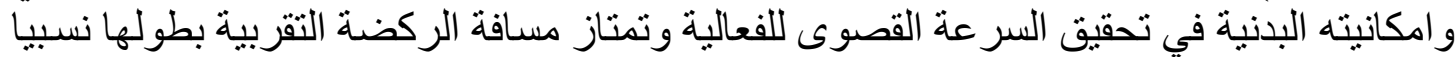

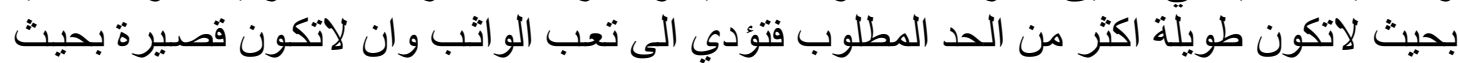

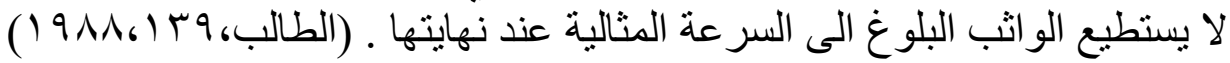




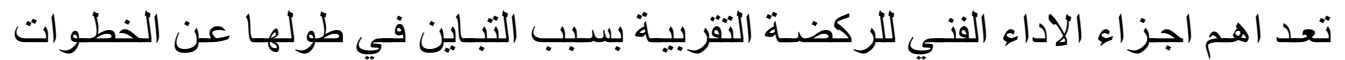

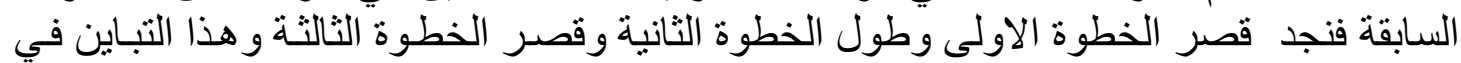

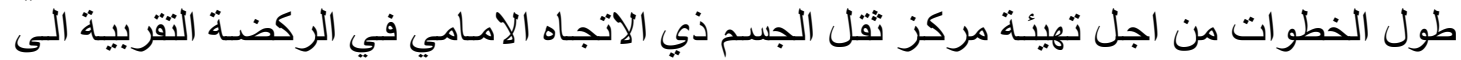

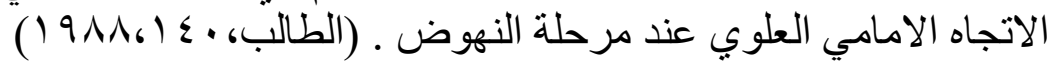
ان التباين في طول الخطو ات الثثلاثة الاخيرة يعتمد على متغير ات ميكانيكية عديدة منها

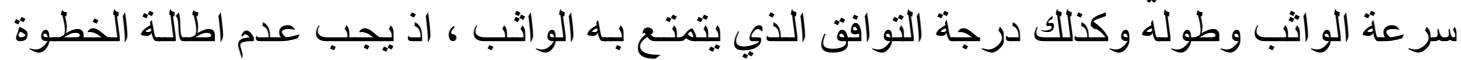

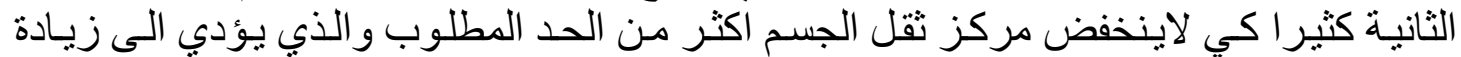

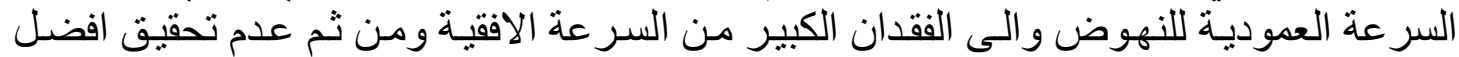

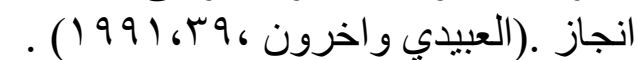

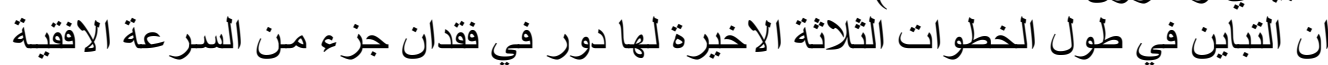

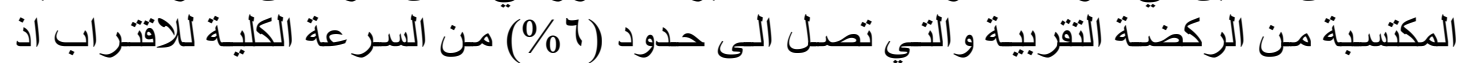

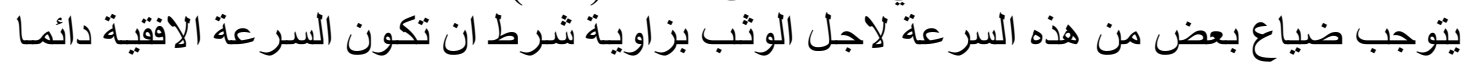

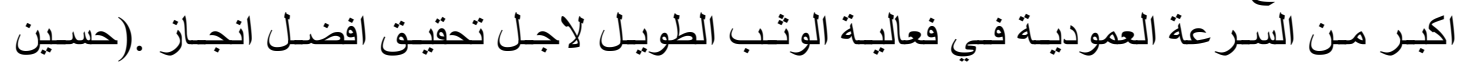

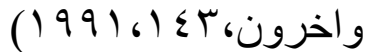

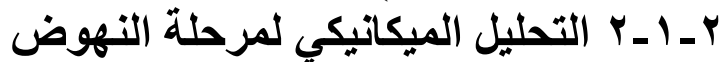

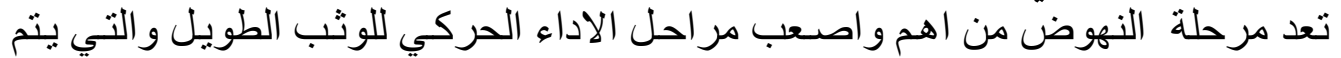

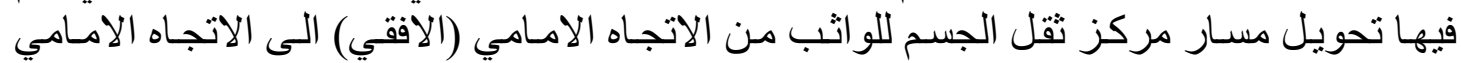

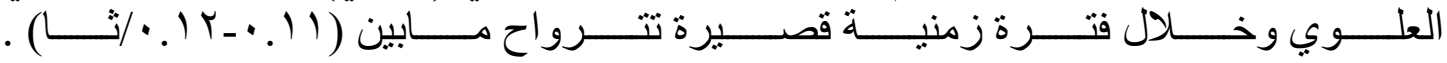

(Cooper and etal,1976,251)

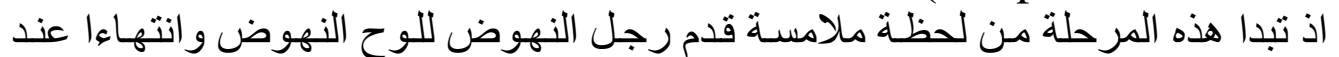

ترك قدم رجل النهوض للوحة النهوض وتعد الحد الفاصل في تحقيق المستوى الجيد ومن خدم خلالها

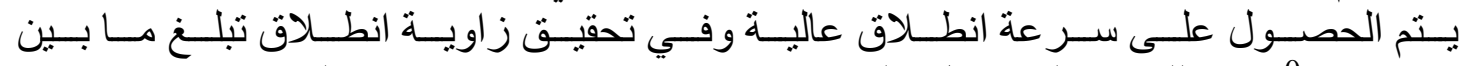

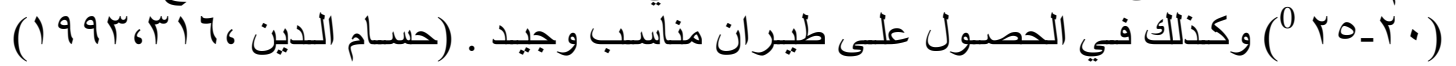

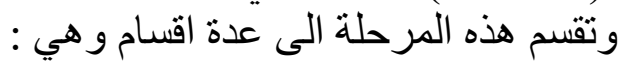

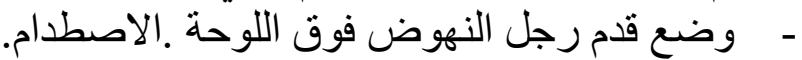

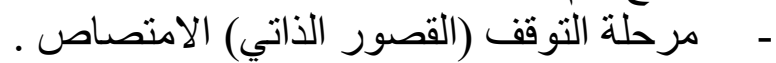

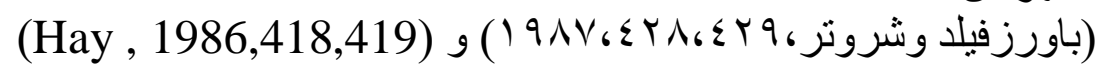

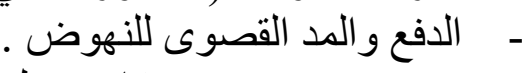

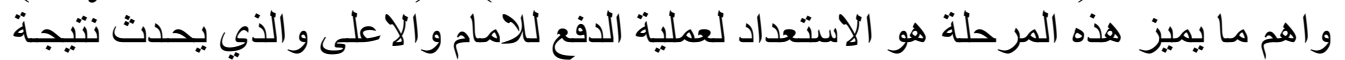

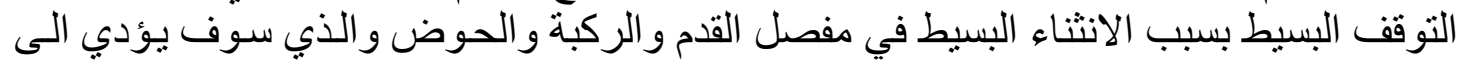

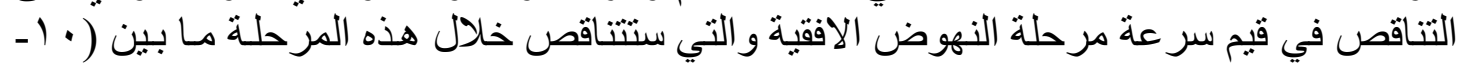

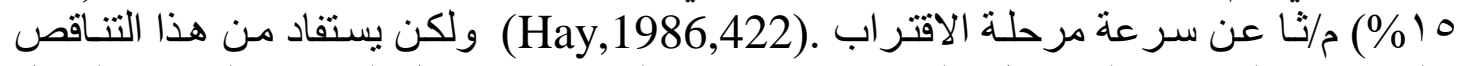

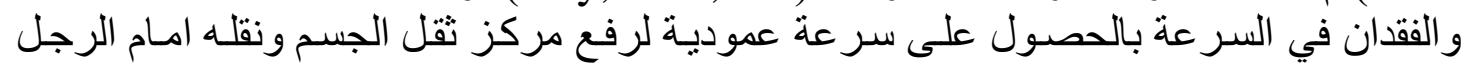

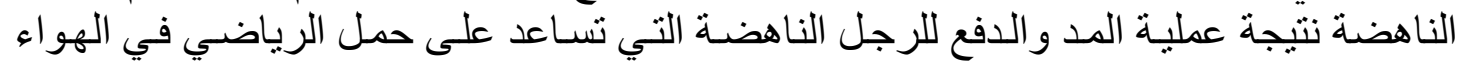

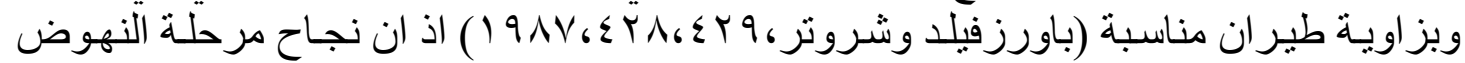

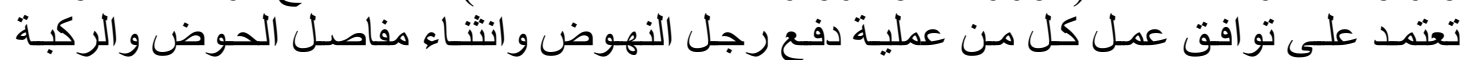

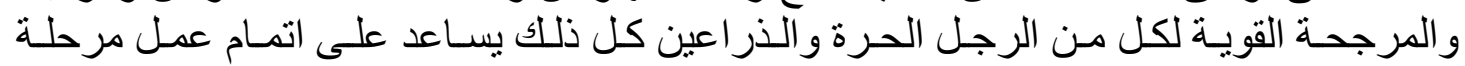

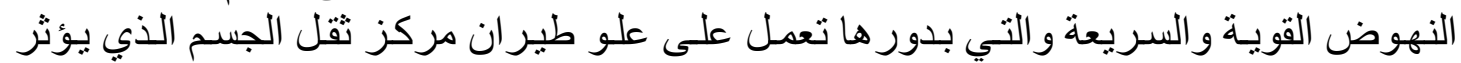

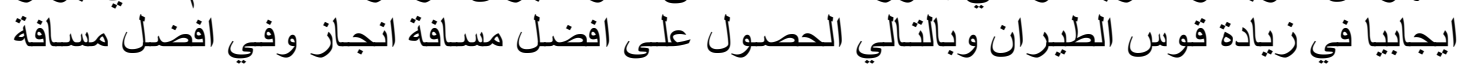

$$
\begin{aligned}
& \text { انجاز وفي اقصر زمن وباقصى سر عة عة ممكنة . } \\
& \text { Y ـ ـ ا ب التحليل الميكاتيكي لمرحلة الطيران }
\end{aligned}
$$

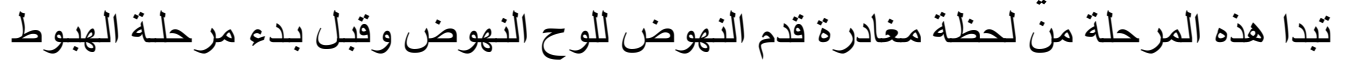

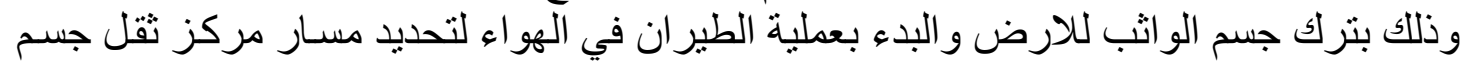




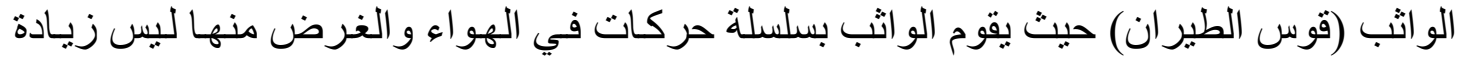

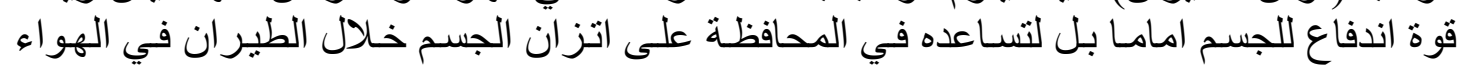

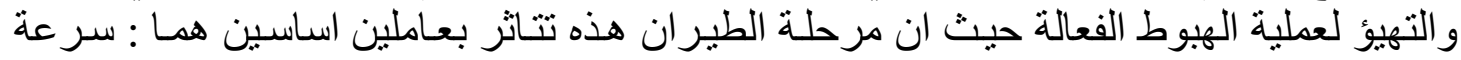

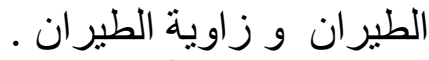

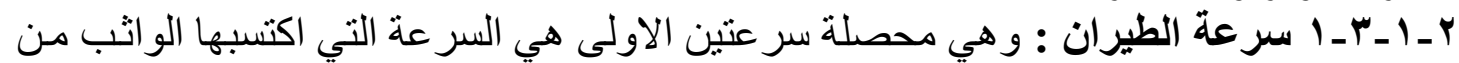

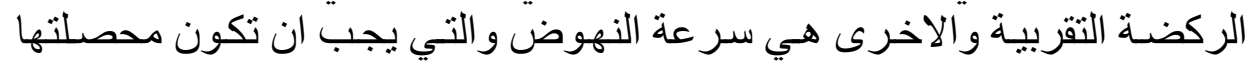

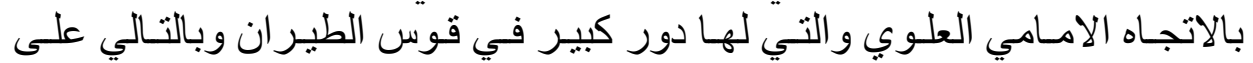

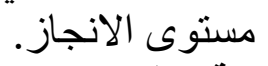

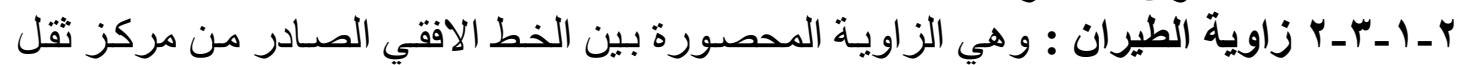

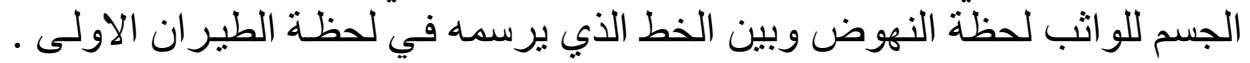

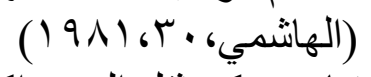

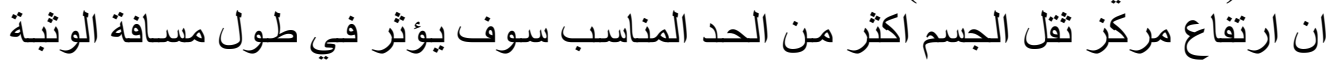

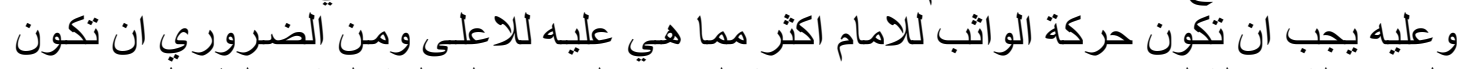

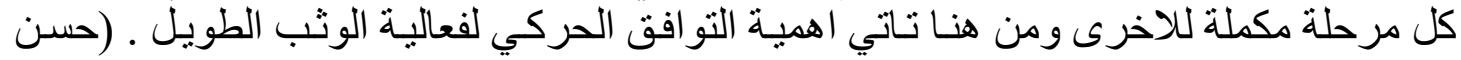

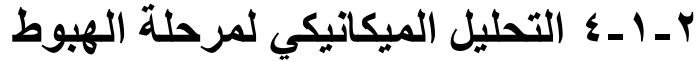

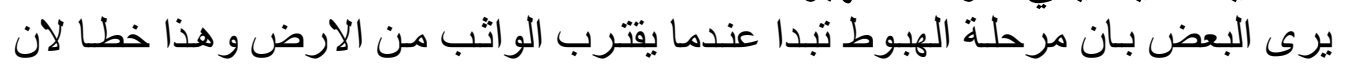

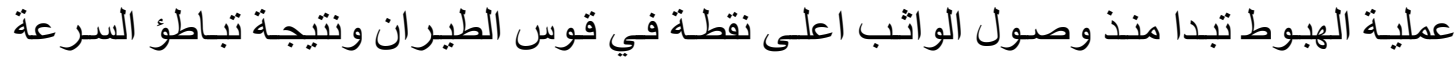

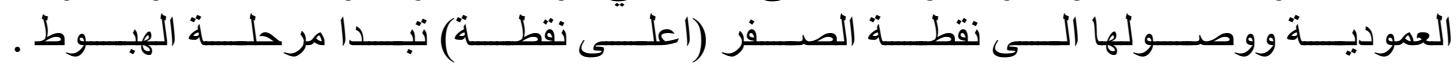

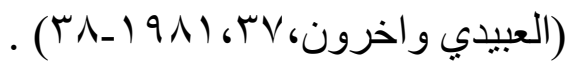

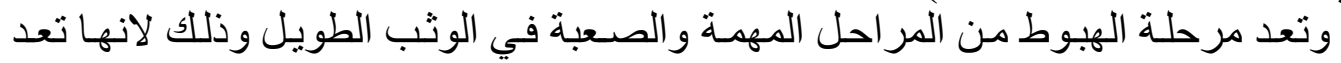

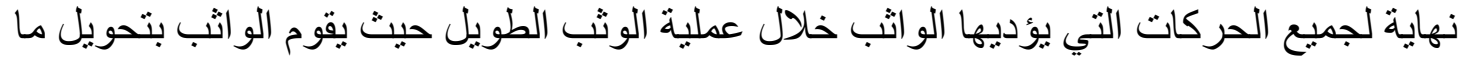

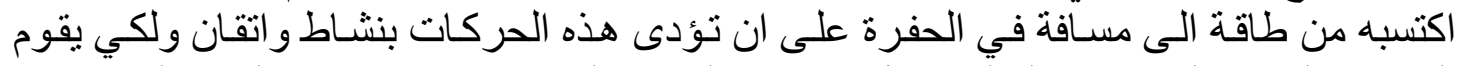

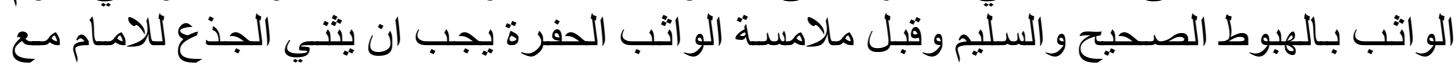

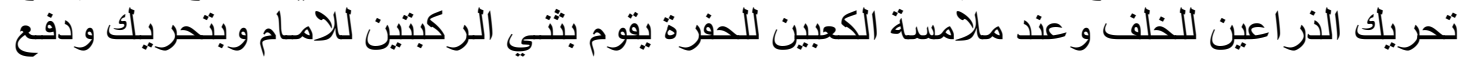

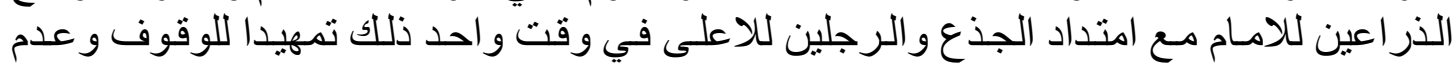

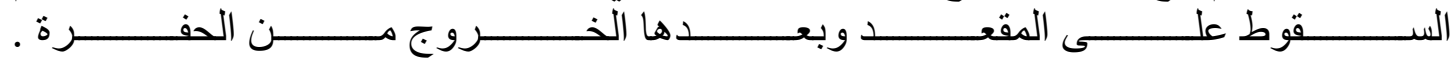

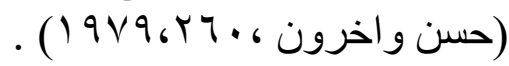

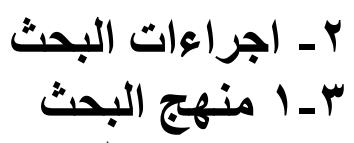

ارتاى الباحث استخدام المنهج الوصفي بطريقة المسح لملائمته وطبيعة المشكلة

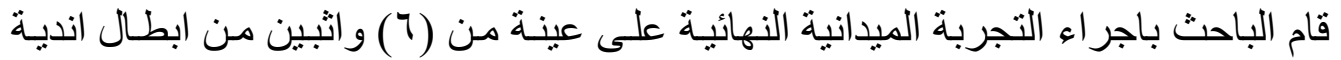

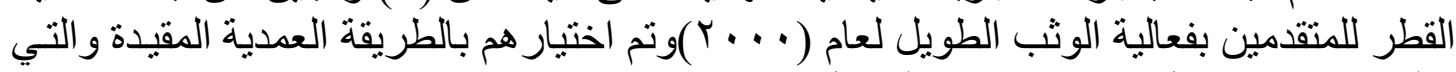
(1) الجدول (1) (1)

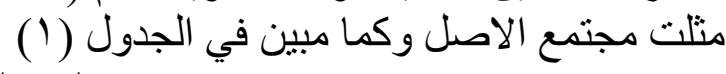

\begin{tabular}{|c|c|c|c|c|c|c|}
\hline الترتيب & مستوى الانجاز/م & طول الواثب/سم & كتلة الواثبين/ كغم & النادي النادي & الاسم & $ت$ \\
\hline كادس & $7 . \% Y$ & 187 & IV & كربلاء & فوزي طامي & 1 \\
\hline
\end{tabular}

يبين كتل الجسم وطول الو اثبين ومستوى الانجاز لعينة البحث 


\begin{tabular}{|c|c|c|c|c|c|c|}
\hline الثالث & $7 . \leqslant Y$ & 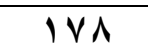 & VI & النجف & حيدر ناجي & $r$ \\
\hline الخامس & 7.10 & IVO & $7 Y$ & الموصل & ربيع عبد الوهاب & $r$ \\
\hline الثاني & 7.00 & $1 \wedge r$ & $V r$ & الموصل & عدنان احمد & $\varepsilon$ \\
\hline الرابع & $7 . \leqslant 1$ & $I V \Lambda$ & 71 & الشرطة & علي صادق & 0 \\
\hline الاول & 7.91 & $1 \wedge r$ & 70 & الشرطة & ماجد عبد السـاده & 7 \\
\hline & $7 . \leqslant 9$ & $1 \vee \wedge .77$ & $7 V .79$ & & "س & \\
\hline &..$Y 19$ & Y.Y.E & $r .9 \wedge r$ & & $\varepsilon \pm$ & \\
\hline
\end{tabular}

$$
\begin{aligned}
& \text { rـr الأجهزة والأدوات المستخدمة في البحث } \\
& \text { استخدمت الادوات الاتية : الادون } \\
& \text { - - الة تصوير فيديوية نوع (National) يابانية الصنع . }
\end{aligned}
$$

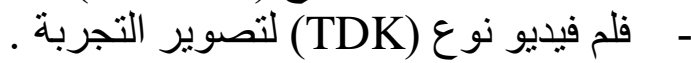

$$
\begin{aligned}
& \text { - - - مريط قياس (متري) لقياس الانجاز. } \\
& \text { - - مقياس الرسم ( ام). }
\end{aligned}
$$

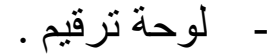

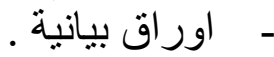

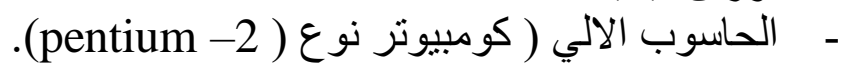

$$
\begin{aligned}
& \text { - مابعة ليزرية نوع (HP leaser jet) - } \\
& \text { - } \\
& \text { r-؛ التجربة الاستطلاعية }
\end{aligned}
$$

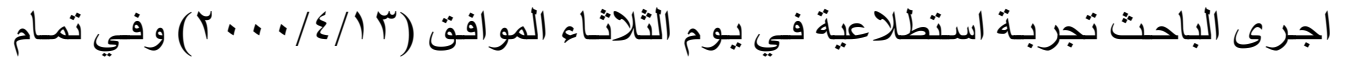

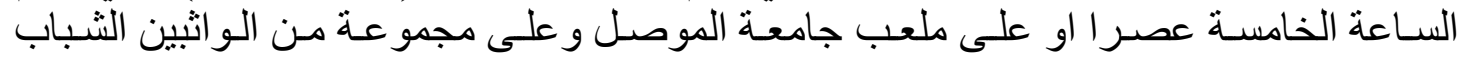

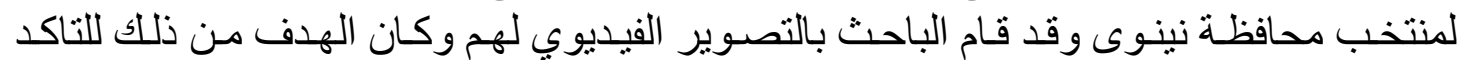

$$
\text { والتعرف على الامور الاتية : }
$$

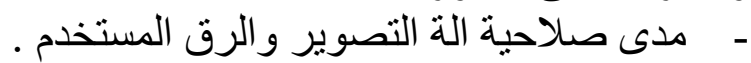

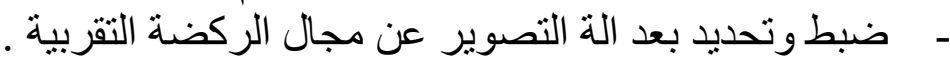

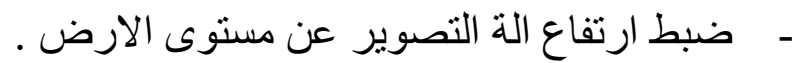
- - الزمن المستغرق لاداء الاختبار (محاولة الوثبر).

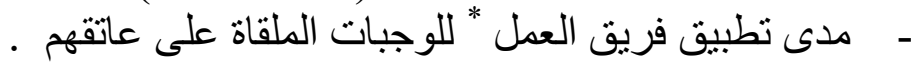

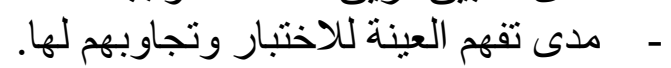

وقد ظهرت هنالك بعض المعوقات خـال القيام بالتجربـة و التي تم تلافيهـا في التجربـة

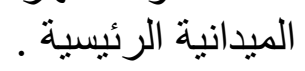

\section{بــ التجرية الرئة الميدانية الرئيسية}

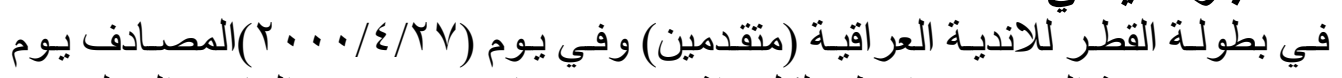

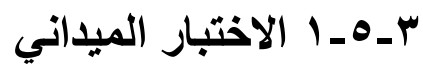

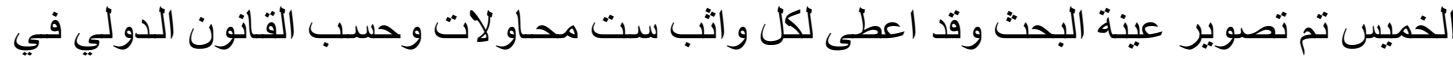

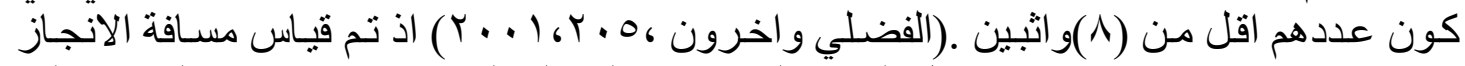

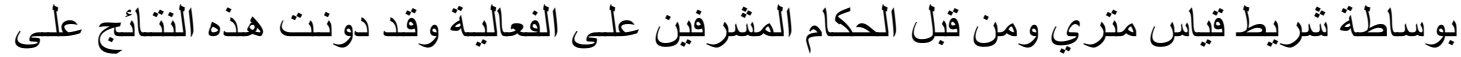

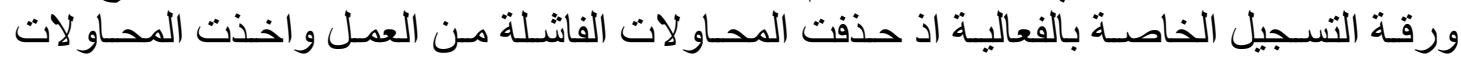

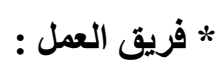

1. السيد ياسر محما: محم طالب دكتوراه جامعة بغداد /الهصور

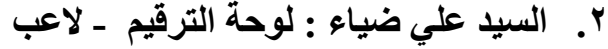

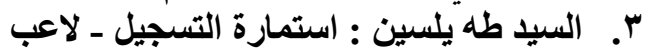


الناجحة فقط وكانت هنالك لوحة ترقيم يسجل عليها رقم اللاعب الذي اعطي له قبل البدء بالمسابقة

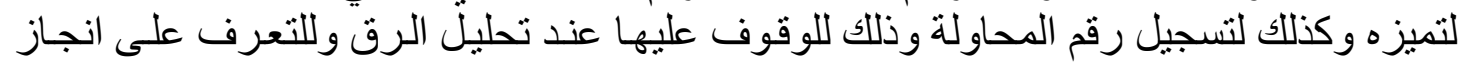

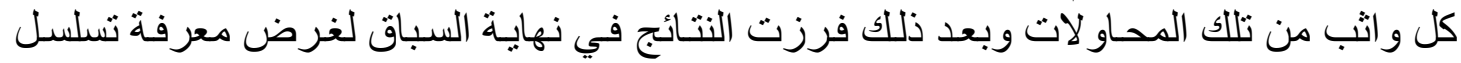

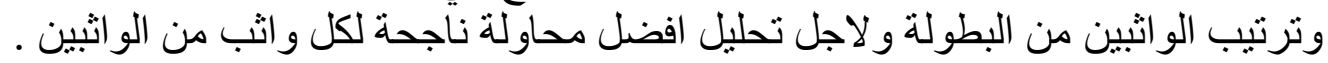

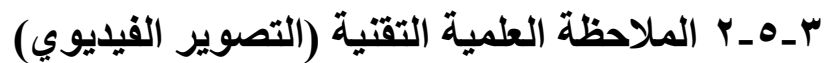

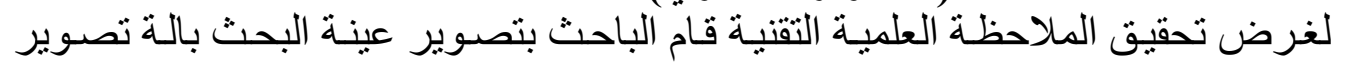

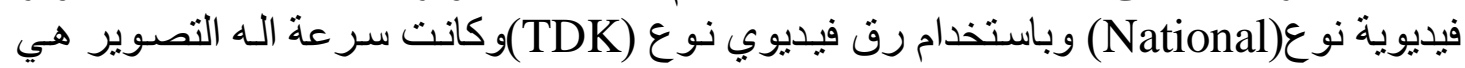

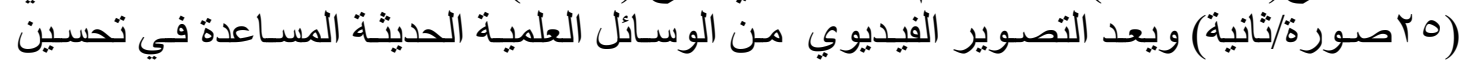

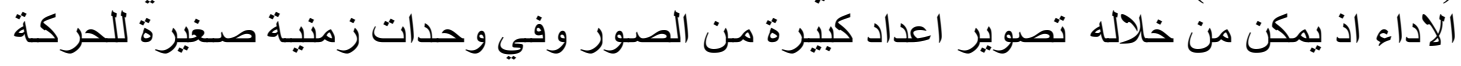

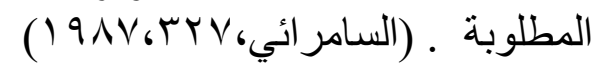

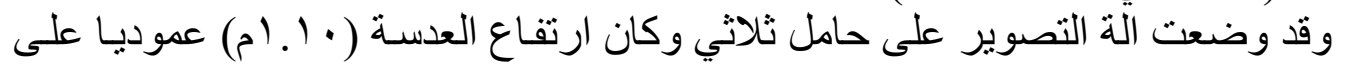

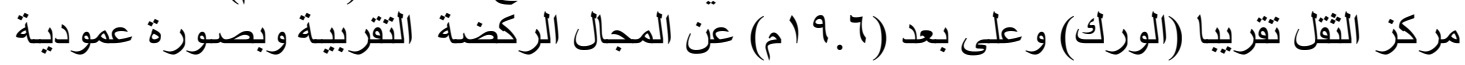

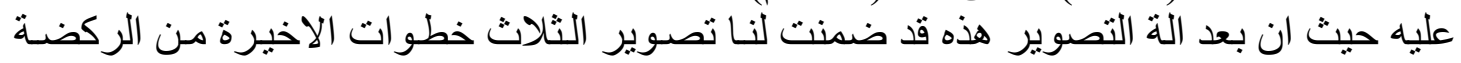

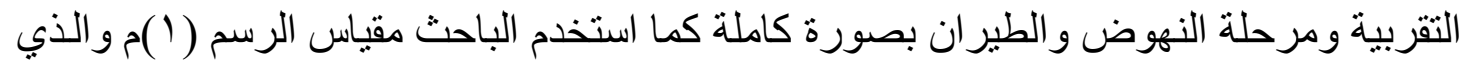

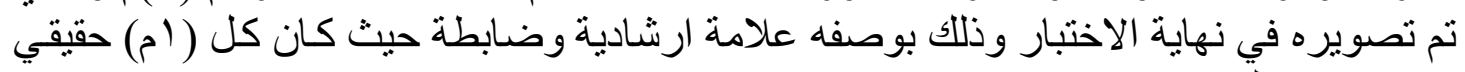

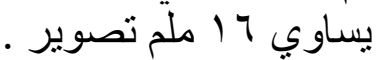

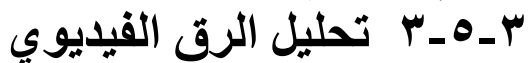

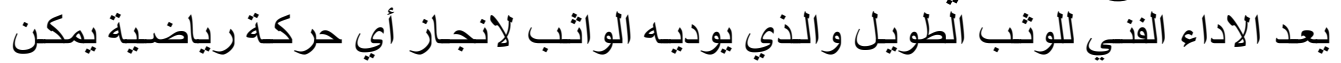

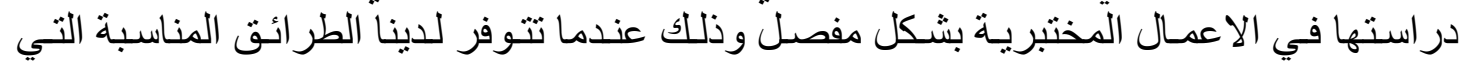

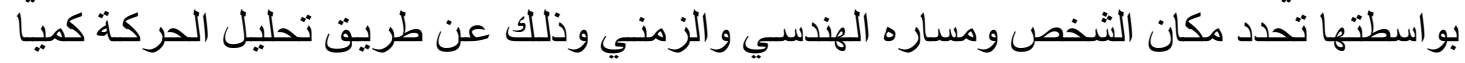

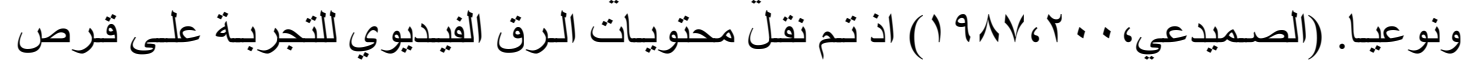

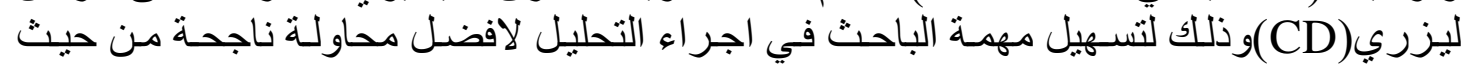

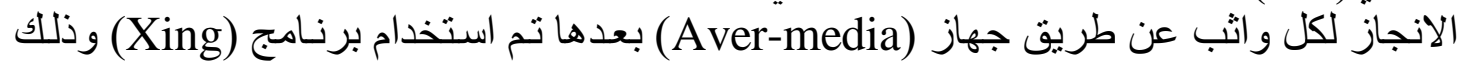

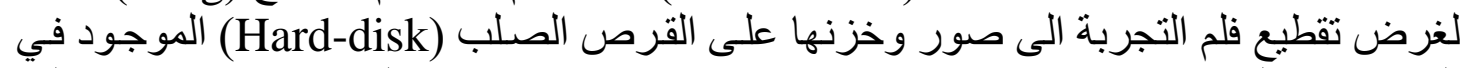

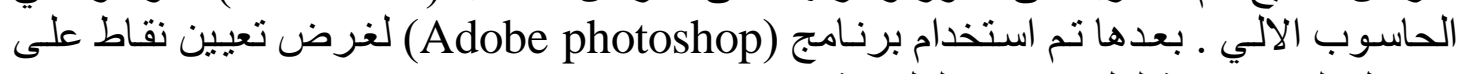

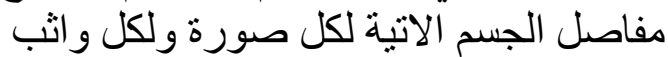
ا ـ نقطة الر اس

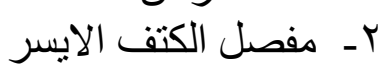

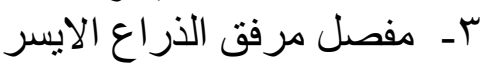

1- مفصل ركبة الرجل اليسرى اليسرى

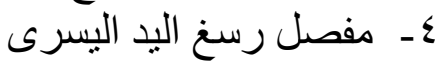

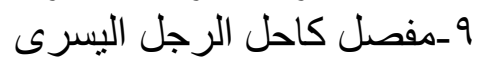

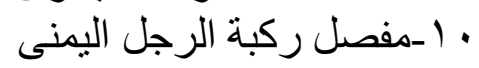

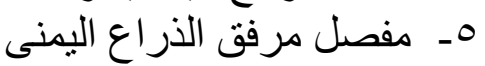

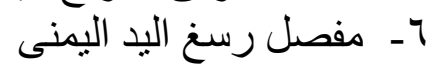

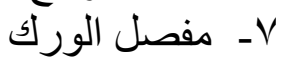

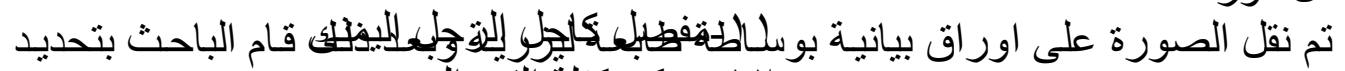

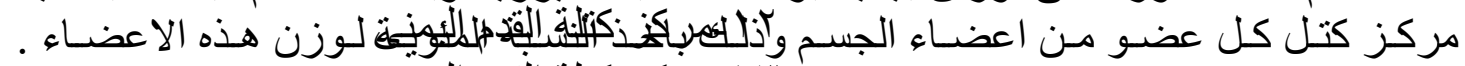
(Wrihed,1984,102)

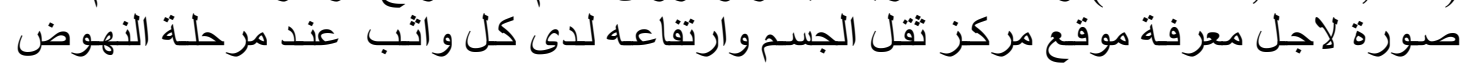

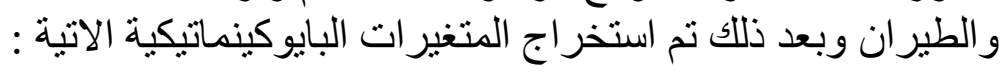

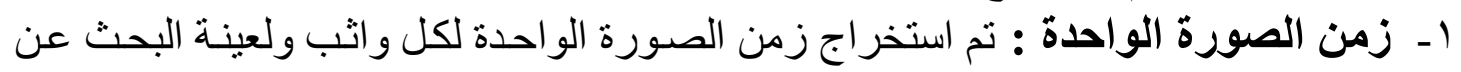

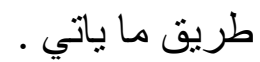
سر عة تردد الة التصوير زمن الصورة الو احدة ماني 
r- المسافة الافقيـة لمرحلة النهوض : وهي المسافة المحصورة مـا بين مركز ثقل الجسم

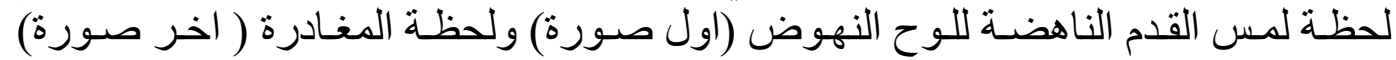
لمرحلة النهوض .

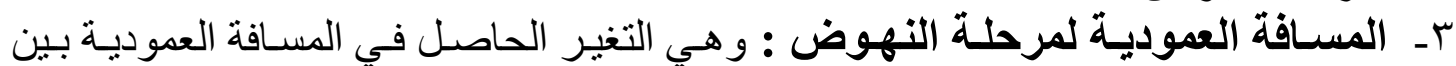

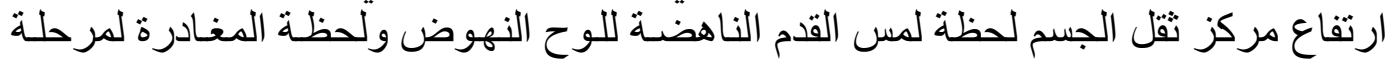

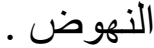

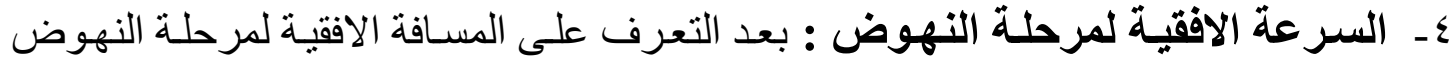

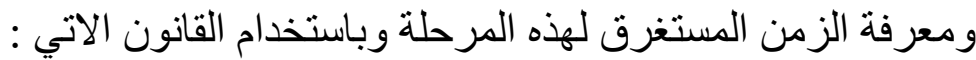

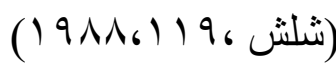

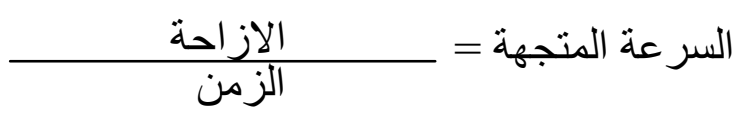
0ـ السرعة العمودية لمرحلة النهوض : كما ذكر في استخر اج السرعة الافقية لهذه المرحلة 7ـ ـ محصلة السرعة لمرحلة النهوض : بعد الحصول على نتائج السر عة الافقية و العموديـة

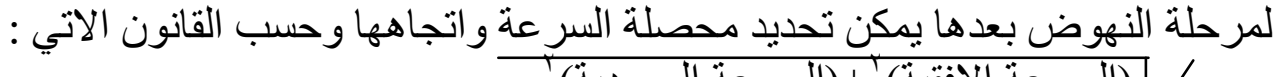

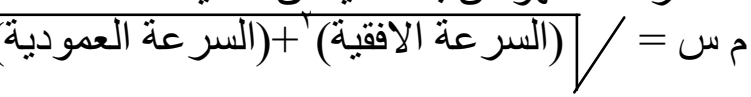

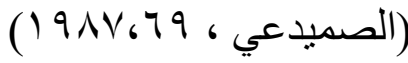

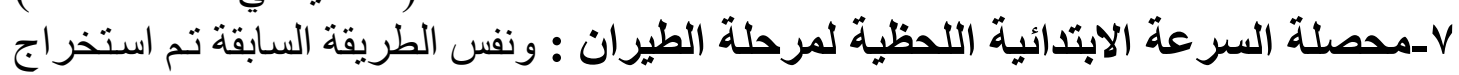

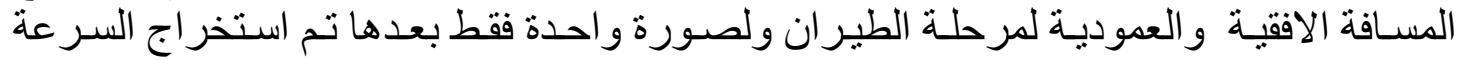

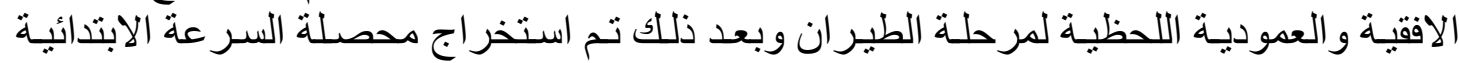

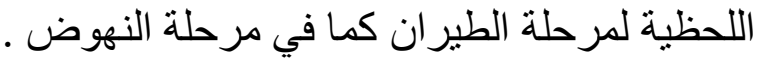

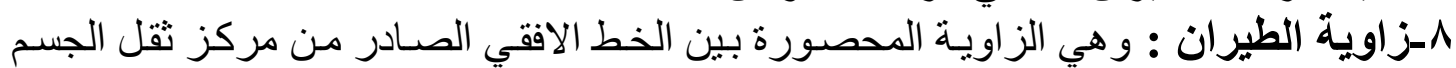

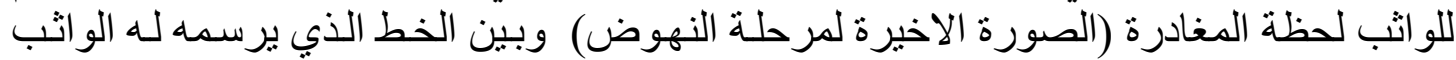

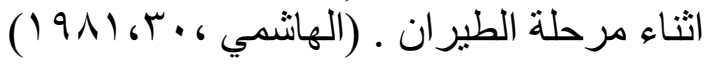

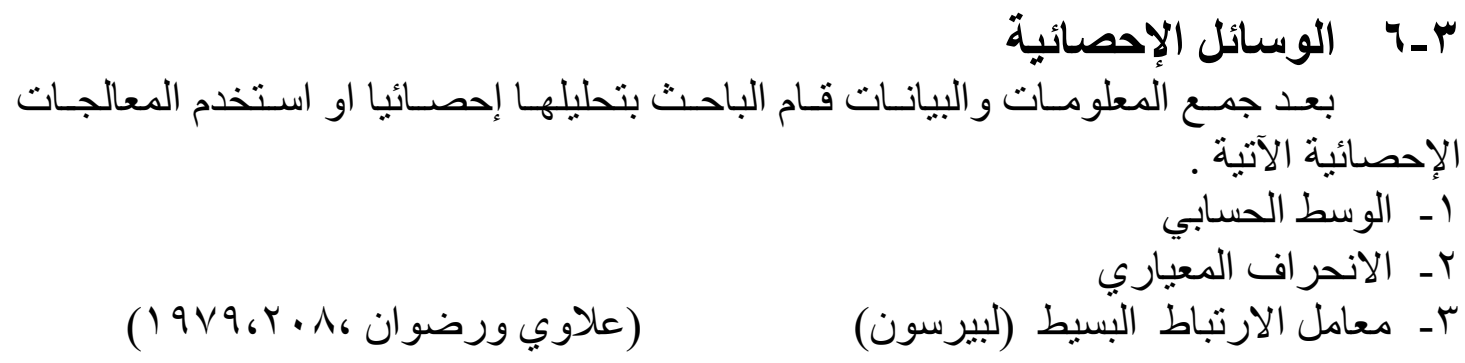
ع ـ - عرض وضناقتشة التتائج استنادا الى هدفا البحث وفرضه قام الباحث بعرض نتائج تحليل التصـوير الفيديوي لعينة البحث التي توصل اليها ـ البت الئ 


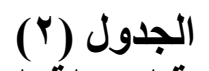

يبين المسافة والسرعة الافقية والعمودية لمرحلة النهوض والطيران كذلك محصلة السرعة لمرحلة النهوض والطيران وزاوية الطيران والانجاز لعينة البحث

\begin{tabular}{|c|c|c|c|c|c|c|c|c|c|}
\hline \multicolumn{2}{|c|}{ المعالم الاحصائية } & \multirow{2}{*}{7} & \multirow{2}{*}{0} & \multirow{2}{*}{$\varepsilon$} & \multirow{2}{*}{$r$} & \multirow{2}{*}{$r$} & \multirow{2}{*}{1} & \multirow{2}{*}{ المتغيرات /تسلسل الواثبين } & \multirow{2}{*}{ ت } \\
\hline$\varepsilon \pm$ & "س & & & & & & & & \\
\hline 1.710 & 1. r.1Yo & qr.vo & $1 \ldots$ & 111.20 & $1 \ldots$ & 1.7 .40 & $1 \ldots$ & الازاحة الافقية لمرحلة النهم / النم & -1 \\
\hline $7 . \leqslant 9$ & $r \cdot . v \theta$ & $r \cdot . v_{0}$ & r. & ro & 11.20 & 19.0 & $1 \wedge . V_{0}$ & الازاحة العمودية لمرحلة & $-r$ \\
\hline$\because \cdot 17$ & $.10 r$ &.${ }^{1 r}$ &. .17 &. .17 & .17 & .17 &. .17 & الزمن المستغرق لمرحلة & $-r$ \\
\hline$\because \neg \wedge r$ & ५.V V & V.AIr & $7 . Y 0$ & $V . \& Y$ & T.Yo & $7.7 \varepsilon$ & 7. Yo & السرعة الافقية لمرحلة & $-\varepsilon$ \\
\hline$\because \leqslant 10$ & $1 . \leqslant \leqslant 9$ & $1.0 r$. & $1.90 r$ & $1.07 r$ & 1.181 & $\because \vee \wedge 1$ & 1.181 & السرعة العمودية لمرحلة & -0 \\
\hline .971 & $7.9 \mu 7$ & V.974 & $7.0 \leqslant 1$ & V.०Ar & $7 . \leqslant \vee q$ & 7.710 & $7 . r \Delta \Lambda$ & محصلة السرعة لمرحلة & -7 \\
\hline. .791 & Y.r. 1 & $v^{r q .71}$ & ro & ห৭. ४^v & ro & ro & $r r . \varepsilon r v$ & الازاحة الافقية لمرحلة & $-V$ \\
\hline $1 . \wedge 9 r$ & N.rrr & $1 \cdot .9 r$ & V.AIr & $7 . Y 0$ & q.rvo & $9 . r \vee 0$ & q.rVo & الازاحة العمودية لمرحلة & $-\Lambda$ \\
\hline صفر & $\because \cdot \varepsilon$ & $\because \varepsilon$ & $\because \varepsilon$ & $\because \varepsilon$ & $\because \bullet$ & $\because \varepsilon$ & $\because \varepsilon$ & الزمن الطستغرق لمرحلة & -9 \\
\hline$\cdot . T V T$ & $7.0 \vee 0$ & $V . \& Y Y$ & $7 . Y^{\circ}$ & $V . \& Y Y$ & T. Y & T. Y & $0 . \wedge 09$ & السرعة الاقفية لمرحلة & -1. \\
\hline$\because \leqslant V r$ & $r . \wedge r$ & Y.VTs & $1.90 r$ & $1.07 r$ & $1.07 r$ & $r . r \leq r$ & $r . r \leq r$ & السرعة العمودية لمرحلة & -11 \\
\hline .970 & 7.911 & $v .9 .9$ & $7.0 \leq V$ & $\vee .0 \wedge 1$ & $7 . \leqslant \leqslant Y$ & $7.7 \vee 0$ & 7.511 & اللحظية لمرحلة الطرة الطيراند م/ثائا & $-1 r$ \\
\hline $1 . V Y r$ & 18.187 & $r \cdot$ & IV & IV & 10 & 11 & $17^{0}$ & زاوية الطيران /درجة & $-1 r$ \\
\hline$\cdot .119$ & $9 . \$ 94$ & 7.91 & $7 . \$ 1$ & 7.00 & 7.50 & $9 . \leqslant Y$ & $7 . r Y$ & الاتجاز /م & $-1 \varepsilon$ \\
\hline
\end{tabular}

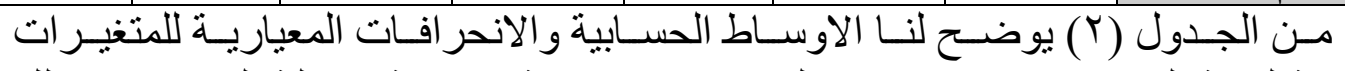

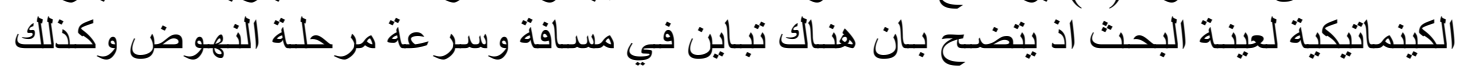
لمرحلة الطير ان لعينة البحث وكذلك بالنسبة لز اوية الطير ان وان والانجاز وكمـا موضـح في الجدول

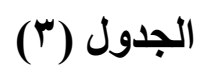

يبين العلاقة بين المتغيرات الكينماتيكية ومستوى الانجاز لعينة البحث

\begin{tabular}{|c|c|c|c|c|}
\hline المعنوية & ر الجدولية & ر المحتسبة & الانجاز / المتغيرات & $ت$ \\
\hline معنوي & \multirow{3}{*}{$\cdot . \wedge 11$} & $\cdot .9 T r$ & محصلة سر عة النهوض م/ثا & -1 \\
\hline معنوي & & $\cdot .9 Y \leq$ & 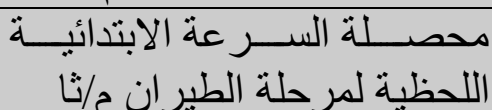 & $-r$ \\
\hline معنوي & & .917 & زاوية الطبران & $-\Gamma$ \\
\hline
\end{tabular}




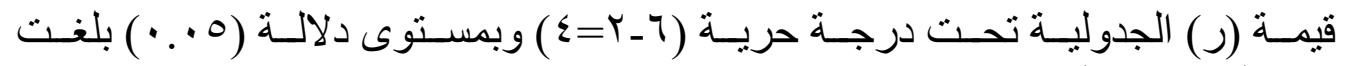

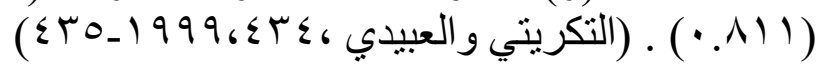

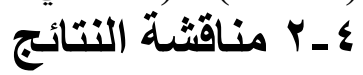

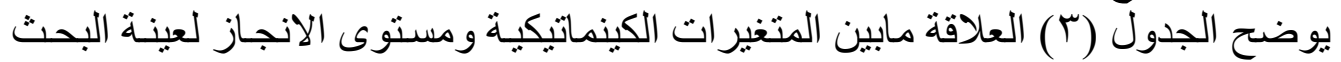

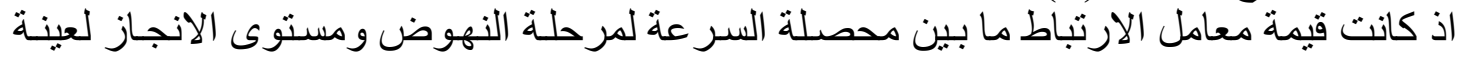

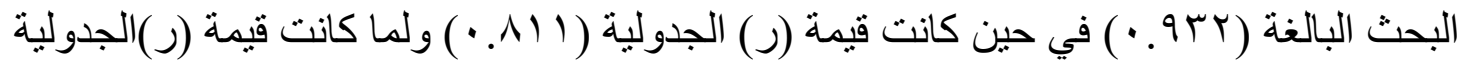

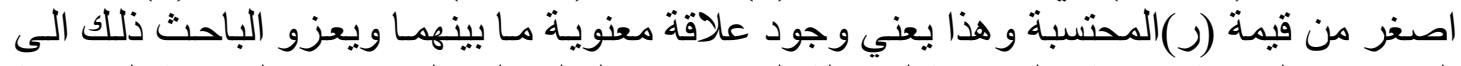

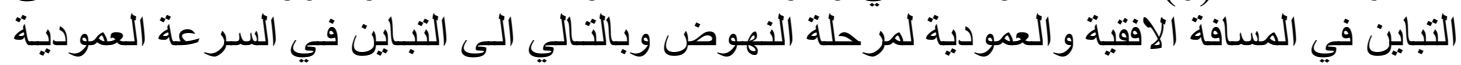

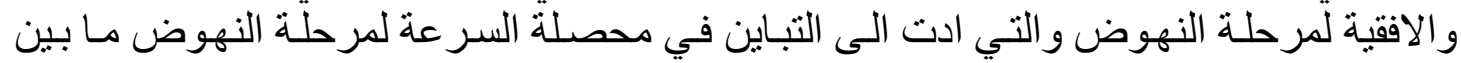

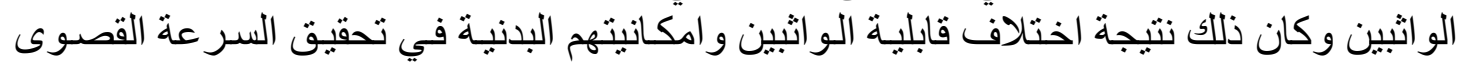

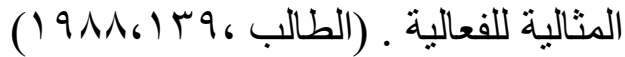

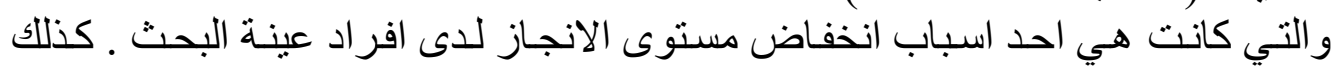

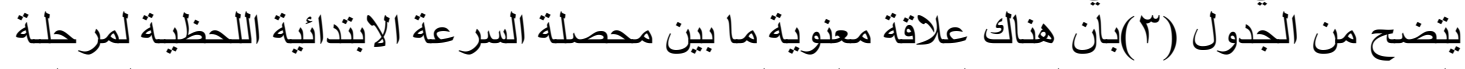

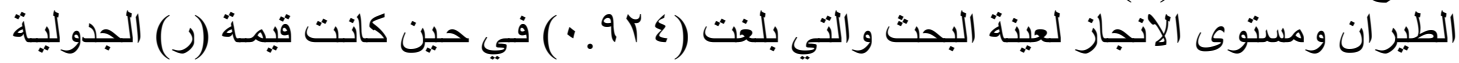

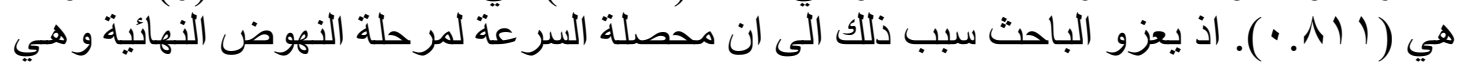

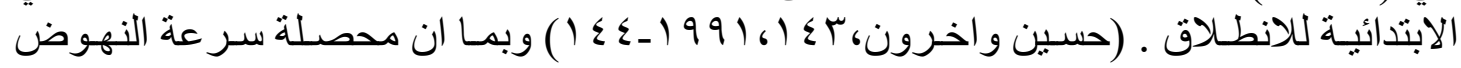

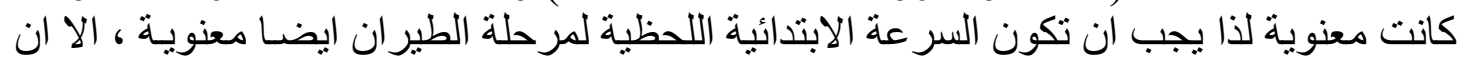

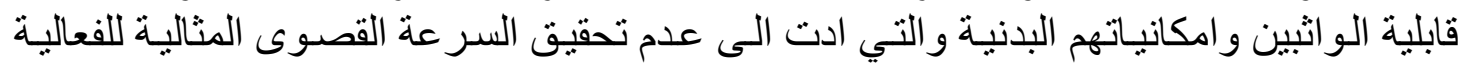

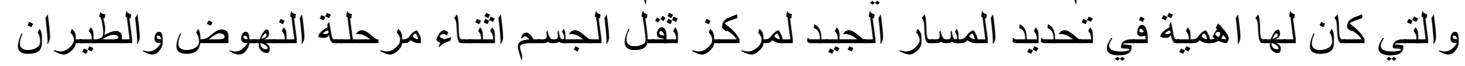

و التي تساهم في تحديد سر عة الانطلاق النهائية ـ (Hirata and etal ,1987,748)

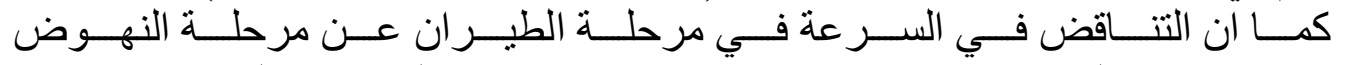

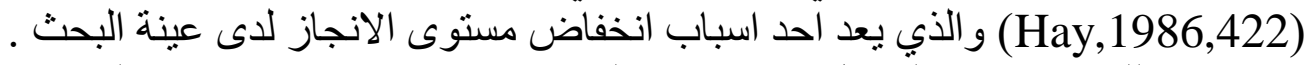

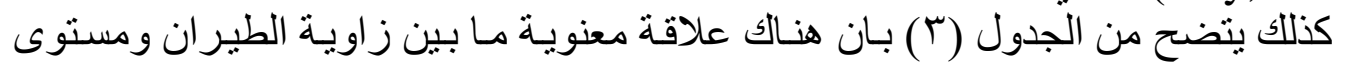

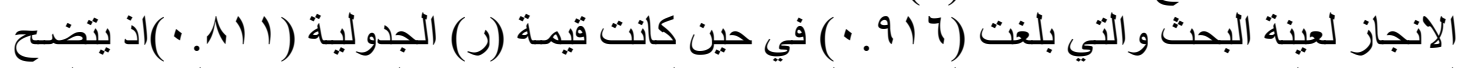

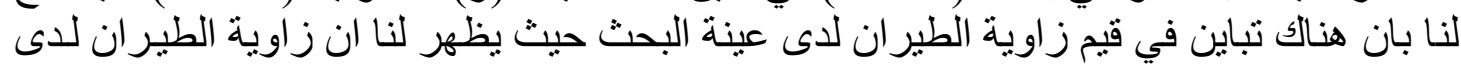

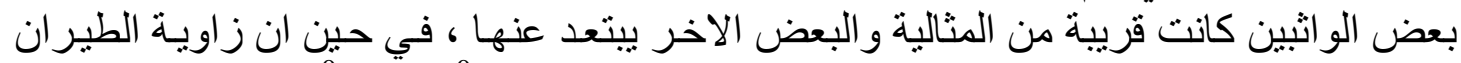

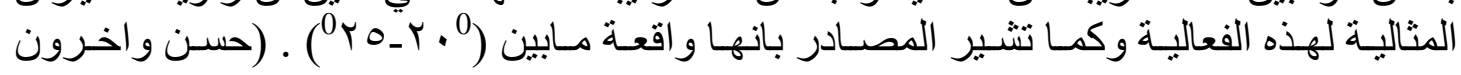

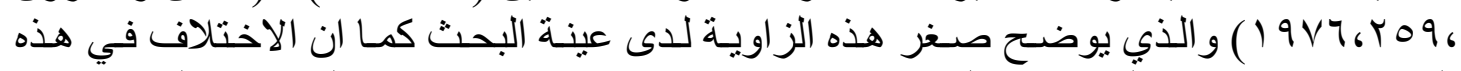

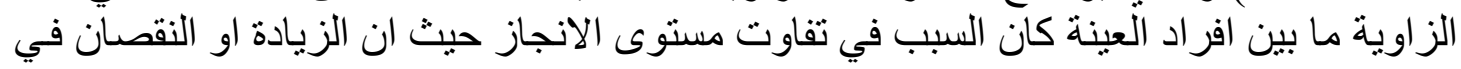

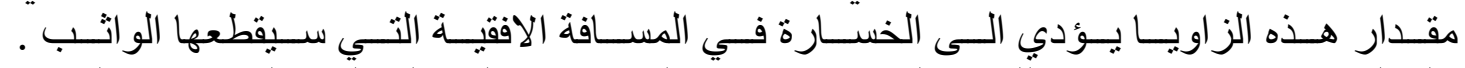

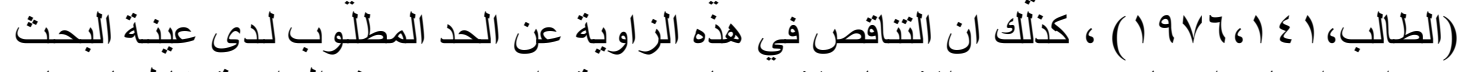

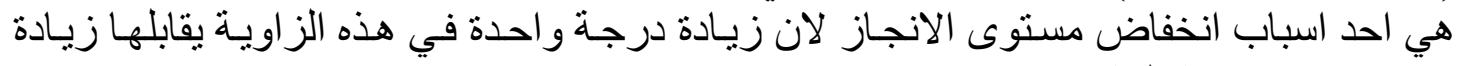

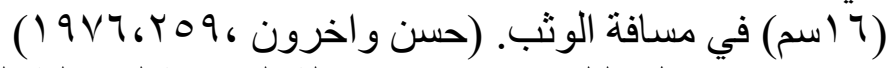

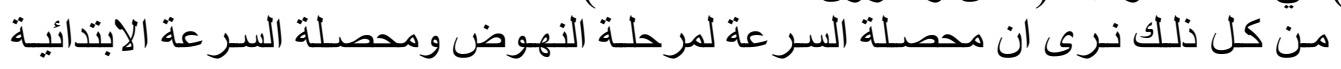

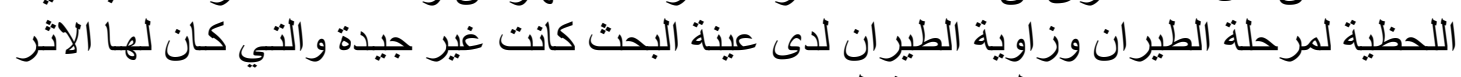

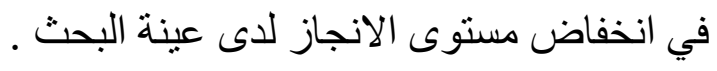

\section{0ـالاستتتاجات والتوصيات 0ـ الاستنتاجات}

على ضوء نتائج التجربة الميدانية لعينة البحث وعن طريق التصـوير الفيديوي وتحليل

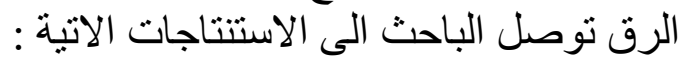
1- - ظهر بان هناك علاقة معنوية بين محصلة السر عة لمرحلة النهوض ومستوى الانجاز. 
r- ـ ظهر بـان هنـاك علاقـة معنويـة بين محصـلة السـرعة الابتدائيـة اللحظية لمرحلـة الطبران

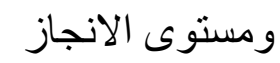

rــ ظهر بان هناك علاقة معنوية بين زاوية الطير ان ومستوى الانجاز . 
على ضوء النتائج التي افرزهات ها البحث يوصي الباحث بما ياتي :

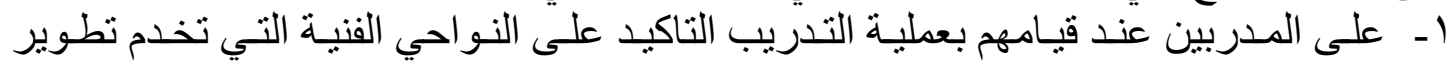

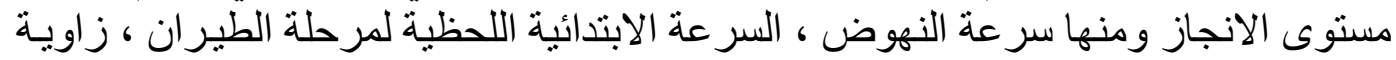

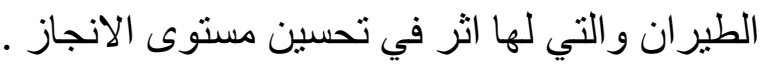

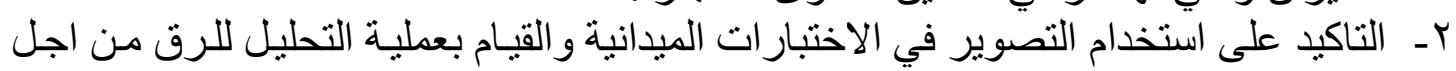

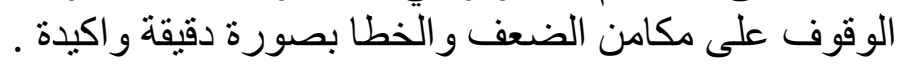

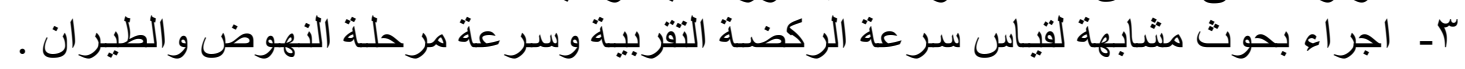
الخ...

\section{المصادر}

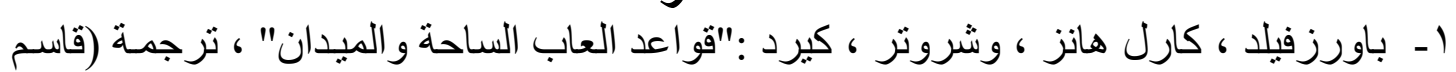

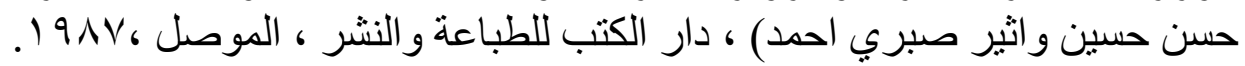

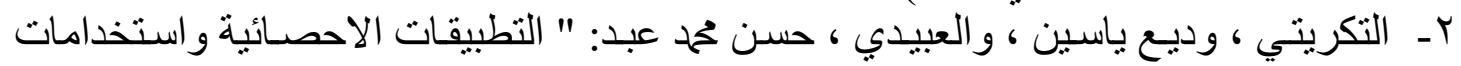

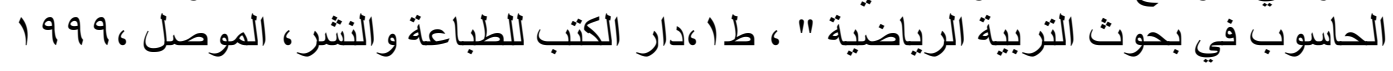

"- حسـام الـدين ، طلحـة :" الميكانيكـا الحيويـة الاسـس النظريـة والتطبيقيـة " ، طا ،دار الفكر

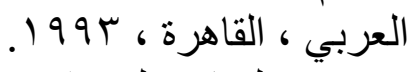

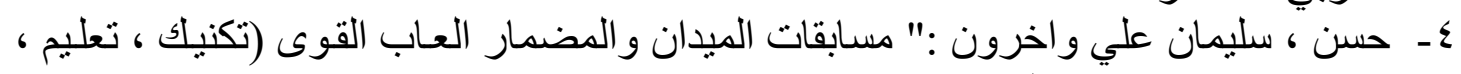

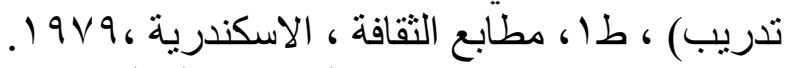

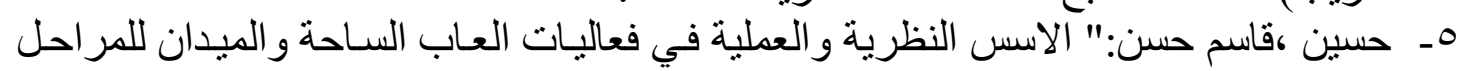

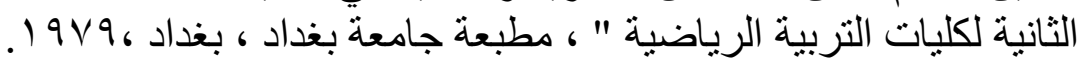




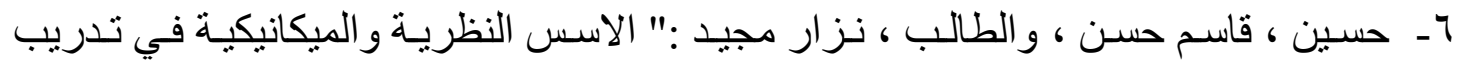

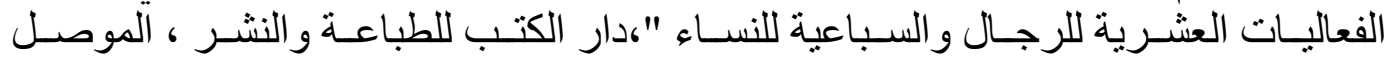
$.191 \mathrm{~V}$ ،

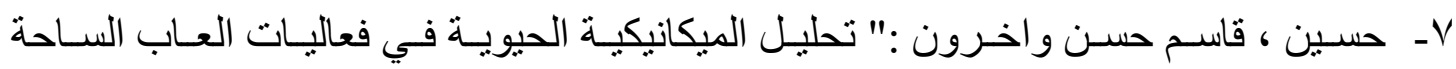

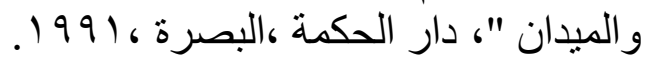

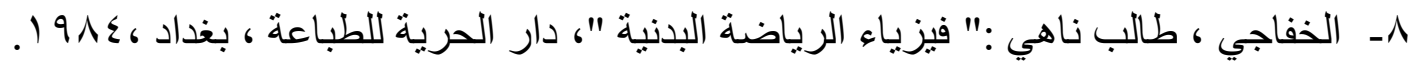

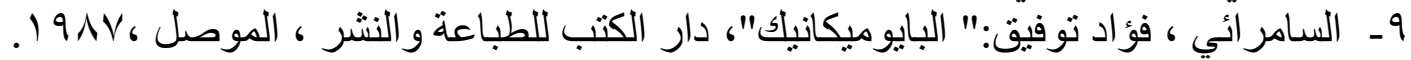

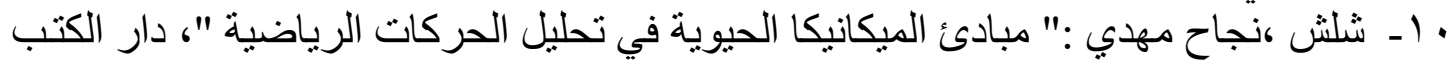

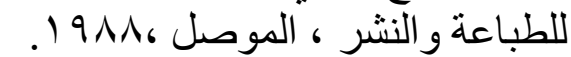
1 إـ الصميدعي ، لؤي غانم :"البايوميكانيك و الرياضة"، دار الكتب للطباعة و النشر ، الموصل $.191 \mathrm{~V}$ ، r ا ـ الطالب ، ضياء مجيد :" المدخل الى الالعاب العشرية للرجـال و السباعية للنسـاء " ، دار

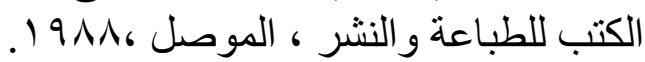

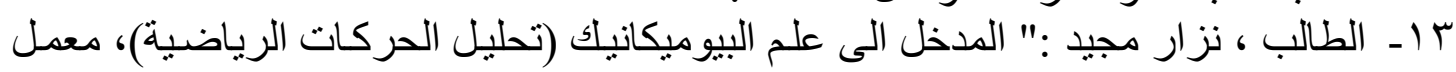

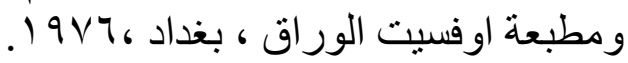

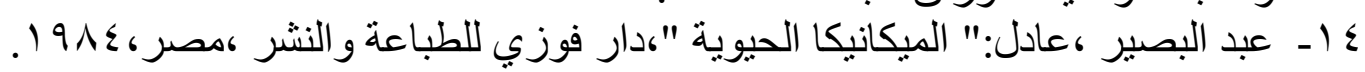

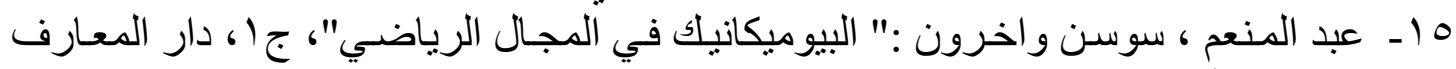

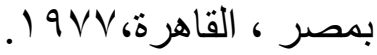

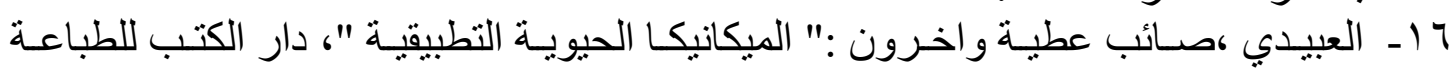

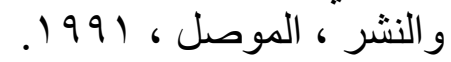

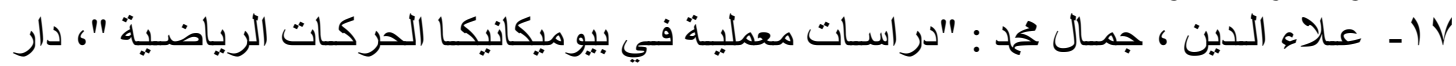

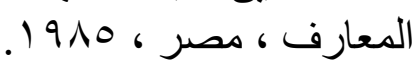

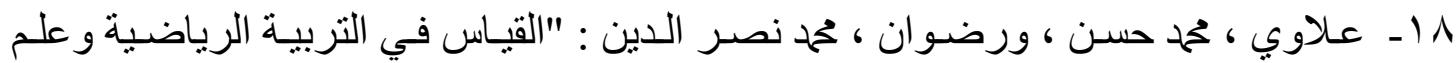

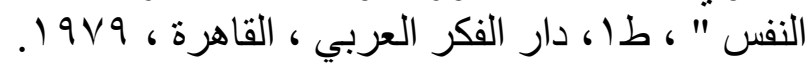

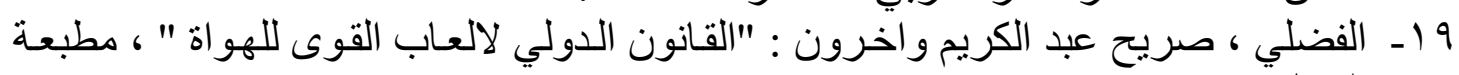

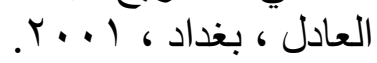

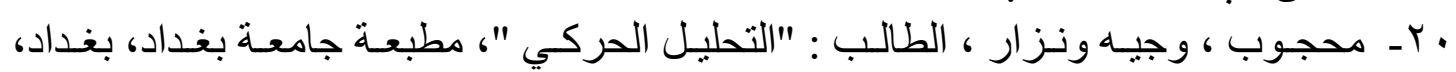
.1914

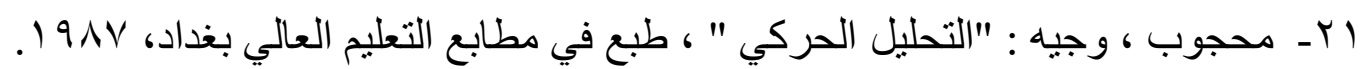

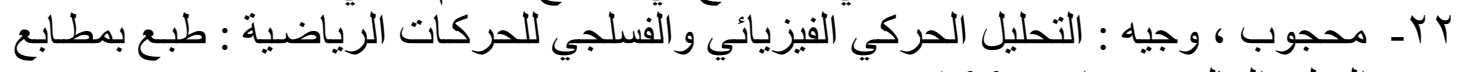

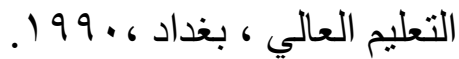

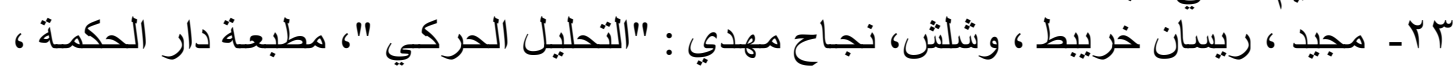

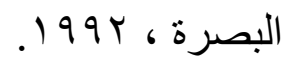
ـ ؟ - موسى ، عالية حسن واخرون : "الفيزياء لطلبة علوم الحياة "، مطابع التعليم العالي ، بغداد .1919،

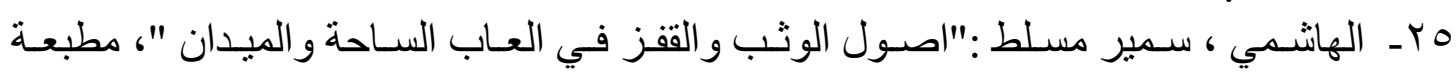

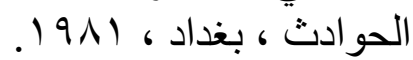
جr ـ الهاشمي ، سمير مسلط :"البايو ميكانيك الرياضي "، دار الكتب للطباعة والنشر ، الموصل .1999 ،

27-Cooper and etal : "Kinesiology " $4^{\text {th }}$ edition ,C.V. mosty Company , 1976. 
28-Hay,Jemes G: "The Biomechanics of the long jump"Exercies and sport science reviews, New York,Macmilla publishing company, 1986.

29-Hirata, Toshiko and etal , : "Effect of take offVelocity on long jump per for manse", international series Biomechanics, volume XB, Humankinetics publisher, Inc , U.S.A., 1987.

30-Wrihed Rolf : "Athletic ability and the anatomy of Motion", wolf medical publications ltd. Orebro Sweden ,1984. 